This is a self-archived - parallel published version of this article in the publication archive of the University of Vaasa. It might differ from the original.

\title{
Volatility clustering, risk-return relationship and asymmetric adjustment in the Finnish housing market
}

Author(s): Dufitinema, Josephine

Title: $\quad$ Volatility clustering, risk-return relationship and asymmetric adjustment in the Finnish housing market

Year: $\quad 2020$

Version: Accepted manuscript

Copyright C)2020 Emerald Publishing Limited. This manuscript version is made available under the Creative Commons AttributionNonCommercial 4.0 International (CC BY-NC 4.0) license, https://creativecommons.org/licenses/by-nc/4.o/

\section{Please cite the original version:}

Dufitinema, J., (2020). Volatility clustering, risk-return relationship and asymmetric adjustment in the Finnish housing market. International journal of housing markets and analysis. https://doi.org/10.1108/IJHMA-12-2019-0125 


\title{
Volatility clustering, risk-return relationship, and asymmetric adjustment in the Finnish housing Market
}

\author{
Josephine Dufitinema \\ School of Technology and Innovation, Mathematics and Statistics Unit, \\ University of Vaasa, Finland
}

Accepted 03 February 2020

\begin{abstract}
Purpose - The purpose of the paper is to examine whether the house prices in Finland share financial characteristics with assets such as stocks. The studied regions are fifteen main regions in Finland over the period of 1988:Q1 to 2018:Q4. These regions are divided geographically into forty-five cities and sub-areas according to their postcode numbers. The studied type of dwellings is apartments (block of flats) divided into one-room, two-rooms, and more than three rooms apartment types. Design/methodology/approach - Both Ljung-Box and Lagrange Multiplier tests are used to test for clustering effects (ARCH effects). For cities and subareas with significant clustering effects, the Generalized Autoregressive Conditional Heteroscedasticity-in-mean (GARCH-M) model is used to determine the potential impact that the conditional variance may have on returns. Moreover, the Exponential GARCH (EGARCH) model is employed to examine the possibility of asymmetric effects of shocks on house price volatility. For each apartment type, individual models are estimated; enabling different house price dynamics, and variation of signs and magnitude of different effects across cities and sub-areas.

Findings - Results reveal that clustering effects exist in over half of the cities and sub-areas in all studied types of apartments. Moreover, mixed results on the sign of the significant risk-return relationship are observed across cities and sub-areas in all three apartment types. Furthermore, the evidence of the asymmetric impact of shocks on housing volatility is noted in almost all the cities and sub-areas housing markets. These studied volatility properties are further found to differ across cities and sub-areas, and by apartment types.

Research limitations/implications - The existence of these volatility patterns has essential implications, such as investment decision making and portfolio management. The study outcomes will be used in a forecasting procedure of the volatility dynamics of the studied types of dwellings. The quality of the data limits the analysis and the results of the study.

Originality/value - To the best of the author's knowledge, this is the first study that evaluates the volatility of the Finnish housing market in general, and by using data on both municipal and geographical level, particularly.
\end{abstract}

Keywords - Finland, House prices, Returns, Volatility, GARCH-M, EGARCH

Paper type - Research paper 


\section{Introduction}

The housing market is a vital factor in the economy of most developed countries. In Finland, housing consisted 50.3 per cent of the Finnish households' total wealth according to the freshest statistics from Statistics Finland (2016). Moreover, the residential properties are the largest sector in the Finnish property investment market. They represented 29 per cent of the total property investment in 2018 (Kaleva, 2019). The main booster of this strong residential property investment is the high demand for small and well-located apartments as young or working-age populations are moving towards urban areas. The reason why the Finnish housing construction has been most active in apartment buildings while the construction for other house types has decreased. In 2018, up to 75 per cent of newly constructed dwellings were studios and one-bedroom flats (Statistics Finland, 2019). In 2019, up to 4,700 apartments will be completed in the Helsinki region, and up to 2,600 in other major areas; and all these flats are being developed 100 per cent for investment market or rental market. This housing development is also boosted by a strong investment demand; currently, foreign investors hold some 15,000 rental flats. Their share in this housing construction varied between 31 and 38 per cent between 2015 and 2018. Some 40 per cent is split between domestic and individual investors; meaning that between 2015 and 2018, up to some 60 per cent of all the Finnish housing construction is targeted for investment market (KTI, Autumn, 2019). Furthermore, in Finland, living in blocks of flats is growing in popularity in comparison to other house types such as attached or terraced and detached houses. At the end of 2018, 46 per cent of all occupied dwellings were in block of flats, 39 per cent in detached and semi-detached houses, 14 per cent in attached houses, and around 1 per cent in other buildings (Statistics Finland Overview, 2018).

The Finnish residential property investment is also fueled by the fact that Finland continues to experience a period of extreme low-interest rates of mortgages, which started in 2012. The average for the last 20 years is 2.37 per cent, and since 2008, the interest rate has stayed under 2 per cent (Bank of Finland, 2018). Therefore, understanding the dynamics of the house price volatility of these types of dwellings preferred by investors is crucial for investment, risk, and portfolio management. In other words, it is essential to investigate whether the studied apartment types display volatility clustering - a volatility pattern which is often observed in stock indices. This clustering or Autoregressive Conditional Heteroscedasticity (ARCH) effect is the characteristic of a series that exhibits certain periods of higher volatility followed by lower volatility for other periods. This aspect is important because, if a process exhibits clustering effects, there is a much higher risk of large losses than standard mean-variance would suggest [see Milles (2008) and Milles (2011b) for the case of the United States and United Kingdom home prices respectively]. Further, as investors are concerned not only about the rate of return on their investment but also the risk associated with the investment; it is essential to analyse the relationship between housing risk and housing return. Finally, it is crucial to examine the possibility of asymmetric effects of shocks on the studied house price volatility. This phenomenon has two popular explanations; the leverage effect and the volatility feedback effect.

Previous research has examined house price volatility of various housing markets and highlighted the importance of testing and analysing ARCH effects in the housing markets (Milles, 2011b); investigating the relation between volatility (risk) and return (Lee, 2017); and exploring whether asymmetric effects of shocks are observable in the housing markets (Lin and Fuerst, 2014). While previous studies in different countries such the United States, United Kingdom, Australia, and Canada have tested the above issues using data sets at the state, metropolitan, and/or provincial level of the family-home property type; 
for housing investment and portfolio allocation purposes, this study uses the Finnish house price indices data on both metropolitan and geographical level of the apartments in the block of flats property type which has increased its investors' and consumers' attractiveness in the Finnish residential properties sector. Moreover, the growing literature on housing volatility studies has been focusing on the countries mentioned above. There has yet to be an analysis of the conditional variance in the Finnish housing market in general, and by property type in particular. Thus, this paper aims to fill that gap by being the first study that comprehensively explores the volatility of the Finnish housing market.

The purpose of the study is, to test volatility clustering in the Finnish housing market by the size of apartments; that is, single-room apartments, two-rooms apartments, and apartments with more than three rooms, for fifteen main regions divided geographically into forty-five cities and sub-areas according to their postcode numbers. Next, for cities and sub-areas exhibiting ARCH effects, individual Generalized Autoregressive Conditional Heteroscedasticity $(\mathrm{GARCH})$ models are estimated. These models are used to answer the following questions: What is the nature of the time-varying volatility? What is the relation between housing returns and house price risk? In other words, does conditional variance affect average returns? Is there asymmetric effect in the volatility of the studied apartment types? These questions are answered by allowing different responses for each time series unit under study. That is, enabling different house price dynamics, and variation of signs and magnitude of different effects across cities and sub-areas; as various studies have found house price dynamics to be heterogeneous across different areas and property types (Milles, 2011b; Katsiampa and Begiazi, 2019). Thus, instead of imposing one single GARCH-type model on the entire data set; an individual model is estimated for each of the cities and sub-areas exhibiting ARCH effects. Results reveal that, clustering effects exist in over half of the cities and sub-areas in all three apartment types. Moreover, mixed results on the sign of the significant risk-return impact are observed across cities and subareas in all three apartment types. Furthermore, the evidence of the asymmetric impact of shocks on housing volatility is noted in almost all the cities and sub-areas housing markets. These studied volatility properties are further found to differ across cities and sub-areas, and by apartment types.

The remainder of the article is organised as follows. The next section reviews the relevant literature. The third describes the data and the methodology to be employed. The fourth presents and discusses the results. The fifth concludes the article.

\section{Literature review}

Asset volatility has been acknowledged as the most widely used risk measure in many areas of finance since it holds essential information (Bollerslev et al., 1992). In the housing literature, recent studies have underlined the importance of analysing and understanding house price volatility for housing investment, proper portfolio management, and policy decision-making (Milles, 2011; Lee and Reed, 2014a). One emphasis of the research on the housing market volatility in different countries has been to investigate whether a specific housing market exhibits volatility clustering (time-varying) effect. The United States housing market has been widely examined with authors such as Dolde and Tirtiroglu (1997; 2002), Miller and Peng (2006), and Milles (2008). Their results suggest the evidence of ARCH effects in the US housing market at the metropolitan statistical area (MSA) and state level. Moreover, similar evidence has also been documented in other housing markets such as the United Kingdom with the works of Tsai et al. (2010), Willcocks (2010), and Milles (2011b). Lee (2009) and Lee and Reed (2014b) studied Australian house price 
volatility; Hossain and Latif (2009) and Lin and Fuerst (2014) examined Canadian house price volatility; while Coskun and Ertugrul (2016) modelled the volatility properties of the house price of Turkey, Istanbul, Ankara, and Izmir. More recently, Katsiampa and Begiazi (2019) studied the Scottish market by property types (detached, semi-detached, terraced, and flats). All these studies confirm the evidence of clustering effects in different housing markets.

Another aspect which is crucial in asset valuation is the risk-return relationship. While many studies have investigated the risk-return interaction for other assets such as stocks (see among others, Guo and Nelly, 2008); the housing risk-return relation is somewhat under-researched. Again, starting from the widely studied housing market, the US housing market, Dolde and Tirtiroglu (1997) analysed the US housing risk-return tradeoff on the municipality level for towns in Connecticut and San Francisco area. They found mixed evidence of a significantly positive risk-return effect in San Francisco and a negative effect in Connecticut. Mixed results were also found by Miller and Peng (2006), who employed GARCH and Vector Autoregressions (VAR) models to analyse the impacts between volatility and house price variables at the MSA level. The abovementioned studies were, however, criticised by Milles (2008). The pointed out limitations were that first, Dolde and Tirtiroglu's (1997) investigation was at the municipal level, and the authors did not first formal conduct tests for the evidence of the ARCH effects in the studied areas. Second, Miller and Peng's (2006) study covered the MSA level data; however, Milles (2008) underlined that for investors, real state risk could be at a broader region than just a municipality or metropolitan area. Specifically, the author examined at the state level, the effect of conditional variance on mean returns by using the GARCH-in-mean model. The analysis was done on twenty-eight states, which exhibited ARCH effects; and similar to the above studies, mixed results of positive and negative risk-return impact were found across eight states. Contrary, on the national level, a positive relationship between house price returns and volatility was found by Cannor et al. (2006), who analysed ZIP code-level housing data by using a cross-sectional asset-pricing approach.

In the UK housing market, the return-volatility relationship was investigated by Milles (2011b). By first conducting clustering effect tests in twelve UK regions, the author found that two out of seven regions with significant ARCH effects exhibited significant riskreturn impacts; those regions were Wales and East Midlands with positive and negative impacts, respectively. Moreover, Morley and Thomas (2011) found evidence of a positive return-volatility effect in most of the English regions and Wales except for the South West area. These heterogeneous impacts of housing volatility on returns across provinces were also found by Lin and Fuerst (2014) in the Canadian housing market. Their results indicated a positive risk-return relationship in the regions of Ontario and Quebec, while a negative one is observed in British Colombus. More recently, Lee (2017) analysed this issue in the Australian housing market by using an asymmetric Component-GARCH-inMean (C-GARCH-M) model and found a strong positive risk-return relationship in the whole Australia as well as in capital cities such as Sydney, Melbourne, Adelaide, Perth, and Brisbane. Lee's (2017) results differ from earlier studies' results by being conclusive and homogenous across the studied areas. The author attributed the difference to the enhancement of the C-GARCH-M model in which the model decomposes the volatility into a short and long-run component and simultaneously incorporates the asymmetric effect of the shocks in the housing market under analysis

Another characteristic of volatility, which is also under-explored in the housing literature, is that of the asymmetric volatility. This volatility phenomenon has been examined in different asset classes, and has two popular explanations; the leverage effect and volatility feedback effect. The former effect follows from Black's (1976) and Christie's (1982) 
finding that a negative shock has more effect on the equity price volatility increase than a positive shock. The latter effect is based on the observed positive correlations between asset volatility and returns (French et al., 1987; Campbell and Hentschell, 1992; Bekaert and $\mathrm{Wu}, 2000)$. In the case of the housing market, the literature is still limited. Similar to the two volatility properties discussed above; the asymmetric effects of the shocks were studied in the US housing market by Milles (2008); in the UK by Tsai and Chen (2009), Milles (2011b), and Morley and Thomas (2011); in the Australian market by Lee (2009) and Lee (2017); in the Canadian market by Lin and Fuerst (2014), and more recently in the Scottish market by Katsiampa and Begiazi (2019). However, Katsiampa and Begiazi's (2019) study differs from the others by considering house prices by property types (detached, semi-detached, terraced, and flats), while the other studies generally consider family-home property type. The US, Australian, and Canadian housing markets seem to be in line in terms of asymmetric effects. In all three housing markets, significant leverage effects were found; implying that the three housing markets are more sensitive to bad news than good news. In the UK housing market, however, results were mixed; on the one hand, no significant leverage effects were observed by Milles (2011b) during the studied sample period. On the other hand, Tsai and Chen (2009) and Morley and Thomas (2011) found respectively significant negative asymmetric effects and little evidence of positive asymmetry in their considered areas.

Collectively, although there is growing research on the housing market volatility, whether the focus is on an investigation of one aspect or a combination of more; the emphasis has been on a limited number of countries. No particular empirical research has been undertaken for the Finnish housing market; even though housing consisted 50.3 per cent of the Finnish households' total wealth (Statistics Finland, 2016). Therefore, this article aims to fill that gap and extend the current literature on the countries' house price volatility analysis by analysing the three volatility characteristics that are commonly investigated in asset valuation; namely, volatility clustering, risk-return relationship, and asymmetric effects. Moreover, this study uses cross-level housing data; that is data on both metropolitan and geographical level, for cross-comparative analysis of the housing investment and portfolio allocation in different Finnish cities and sub-areas. Contrary to the previous studies which employed data on the state, national, regional, or metropolitan level. Furthermore, in the same standpoint of housing investment; this article uses data on apartments in the block of flats property type, which has increased its investors' and consumers' attractiveness in the Finnish residential property sector.

\section{Data and Methodology}

\section{Data}

The study employs the Statistics Finland quarterly house price indices data of fifteen main regions in Finland; throughout 1988:Q1 to 2018:Q4, for a total of 124 observations. The studied regions are ranked according to their number of inhabitants. There are four regions with more than 250,000 inhabitants: Helsinki, Tampere, Turku, and Oulu; of which the three first make up the so-called growth triangle in Southern Finland, and Oulu is the growth centre of Northern Finland. Seven regions with more than 100,000 inhabitants: Lahti, Jyväskylä, Kuopio, Pori, Seinäjoki, Joensuu, and Vaasa. Four regions with a population number between 80,000 - 90,000: Lappeenranta, Kouvola, Hämeenlinna, and Kotka. These regions are then divided geographically into cities and sub-areas according to their postcode numbers (see Table 8 in Appendix); to form a total of forty-five cities 
and sub-areas. The considered type of dwellings is apartments (block of flats) because they are the most homogenous assets in the housing market compared to other housing types, such as detached and terraced. Additionally, in Finland, flats are favoured by investors. The apartment types are divided into single-room, two-rooms, and more than three rooms apartments.

Tables 1-3 provide the summary statistics of the quarterly house price returns for single-room, two-rooms, and more than three rooms flats respectively. Note that cities and sub-areas without available data for at least 20 years ( 80 observations) have been removed from the analysis. Over the studied period, Helsinki-area1 leads the one-room apartments type group with the highest average return (1.16 per cent per quarterly). Kuopio-area1 follows with 1.14 per cent per quarterly average return. Helsinki-area2, Helsinki-city, and Vaasa-area1 come in third place with an average return of at least 1.0 per cent per quarterly. In terms of volatility dimension, Pori-area1 recorded the highest risk measure (standard deviation), followed by Lahti-area1. The largest cities, such as Helsinki and Tampere, as well as Helsinki-area2, appear to be less volatile as they have the lowest risk level; suggesting a less significance of the ARCH effects in these cities and area.

The two-rooms apartments type group appears to have less quarterly average returns, in general; compare to the one-room and more than three rooms flat types. Helsinkiarea1 also scores the highest average return (1.18 per cent per quarterly), followed by Helsinki-area2 and Tampere-area1 with at least 1.0 per cent per quarterly average return. Kotka-area2 leads the group in terms of risk measure. Same as in the one-room apartments type group, the biggest cities (Helsinki, Tampere, Turku, and Oulu) and their surrounding areas seem to be less volatile. Helsinki-area1 also comes on top with 1.15 per cent per quarterly average return in the more than three rooms apartments type group, followed by Tampere-area1 and Helsinki-area2. Hämeenlinna-area1, Joensuu-area1, and Seinäjokicity are the more volatile areas of the group.

The house price movement of a sample of the three most volatile cities/sub-areas in each of the apartments categories over the studied period is shown in Figure 1. Those are Pori-area1, Pori-city, Jyväskylä-area2 in the one-room apartments type group; Kotka-area2, Pori-area1, Kotka-area1 in the two-rooms apartments type group; and Hämeenlinna-area1, Joensuu-area1, Seinäjoki-city in the more than three rooms apartments type group. Initial evidence of volatility clustering effects is observed in all sample cities and sub-areas as they exhibit high fluctuations with certain time periods of high volatility followed by low volatility for other periods. A similar pattern is observed in all the graphs from the end of the 1980s until mid-1993; the period that Finland experienced financial market deregulation which induces a structural break in the house price dynamics (Oikarinen, 2009a; Oikarinen, 2009b). 


\begin{tabular}{|c|c|c|c|c|c|c|}
\hline Cities/Sub-areas & Abbrevations & Mean & Maximum & Minimum & $\mathrm{Sd}$ & nobs \\
\hline Helsinki-city & hki & 1.05 & 10.0 & -9.6 & 3.5 & 124 \\
\hline Helsinki-area1 & hki1 & 1.16 & 12.2 & -9.1 & 4.1 & 124 \\
\hline Helsinki-area2 & hki2 & 1.08 & 9.2 & -9.4 & 3.6 & 124 \\
\hline Helsinki-area3 & hki3 & 0.88 & 11.9 & -13.4 & 4.1 & 124 \\
\hline Helsinki-area4 & hki4 & 0.68 & 10.5 & -12.8 & 4.3 & 124 \\
\hline Tampere-city & tre & 0.93 & 10.9 & -11.6 & 3.9 & 123 \\
\hline Tampere-area1 & tre1 & 0.99 & 12.9 & -14.9 & 4.9 & 123 \\
\hline Tampere-area2 & tre2 & 0.95 & 14.7 & -17.6 & 5.9 & 119 \\
\hline Tampere-area3 & tre3 & 0.78 & 16.2 & -12.6 & 4.9 & 123 \\
\hline Turku-city & tku & 0.88 & 14.0 & -10.1 & 4.4 & 124 \\
\hline Turku-area1 & tku1 & 0.95 & 15.4 & -12.5 & 5.4 & 124 \\
\hline Turku-area2 & tku2 & 0.77 & 22.5 & -21.5 & 6.9 & 111 \\
\hline Turku-area3 & tku3 & 0.79 & 14.3 & -26.1 & 6.5 & 114 \\
\hline Oulu-city & oulu & 0.69 & 11.8 & -10.8 & 4.3 & 124 \\
\hline Oulu-area1 & oulu1 & 0.68 & 14.9 & -12.8 & 5.1 & 124 \\
\hline Oulu-area2 & oulu2 & 0.73 & 15.5 & -18.3 & 5.7 & 116 \\
\hline Lahti-city & lti & 0.66 & 16.2 & -15.6 & 5.4 & 124 \\
\hline Lahti-area1 & lti1 & 0.96 & 36.5 & -28.3 & 7.8 & 109 \\
\hline Lahti-area2 & lti2 & 0.36 & 16.5 & -21.8 & 6.1 & 124 \\
\hline Jyväskylä-city & jkla & 0.76 & 13.4 & -10.6 & 4.7 & 124 \\
\hline Jyväskylä-area1 & jkla1 & 0.85 & 14.6 & -13.9 & 5.1 & 124 \\
\hline Jyväskylä-area2 & jkla2 & 0.86 & 27.0 & -20.4 & 7.3 & 91 \\
\hline Pori-city & pori & 0.67 & 22.7 & -26.8 & 7.7 & 124 \\
\hline Pori-area1 & pori1 & 0.95 & 28.4 & -26.9 & 8.6 & 100 \\
\hline Kuopio-city & kuo & 0.86 & 16.5 & -12.5 & 4.3 & 123 \\
\hline Kuopio-area1 & kuo1 & 1.14 & 17.3 & -20.6 & 5.9 & 111 \\
\hline Kuopio-area2 & kuo2 & 0.89 & 15.4 & -18.6 & 6.7 & 87 \\
\hline Joensuu-city & jnsu & 0.75 & 15.8 & -15.8 & 5.0 & 122 \\
\hline Joensuu-area1 & jnsu1 & 0.78 & 17.2 & -15.7 & 5.4 & 117 \\
\hline Vaasa-city & vaasa & 0.78 & 14.5 & -16.0 & 6.8 & 121 \\
\hline Vaasa-area1 & vaasa1 & 1.00 & 17.3 & -17.4 & 7.6 & 105 \\
\hline Kouvola-city & kou & 0.17 & 15.3 & -16.9 & 6.8 & 118 \\
\hline Lappeenranta-city & lrta & 0.55 & 12.6 & -13.8 & 4.9 & 124 \\
\hline Lappeenranta-area1 & lrta1 & 0.77 & 17.0 & -20.3 & 6.9 & 97 \\
\hline Hämeenlinna-city & hnlina & 0.68 & 12.9 & -17.0 & 6.0 & 124 \\
\hline Hämeenlinna-area1 & hnlina1 & 0.85 & 12.4 & -19.8 & 6.5 & 103 \\
\hline Kotka-city & kotka & 0.55 & 16.7 & -12.5 & 5.6 & 121 \\
\hline Kotka-area1 & kotka1 & 0.87 & 16.1 & -15.4 & 6.9 & 95 \\
\hline
\end{tabular}

Notes: This table presents summary statistics on the one-room flats price index returns. Units are quarterly returns in percentage points. The sample is 1988:Q1 to 2018:Q4.

Table 1: One-room flats quarterly house price returns - Summary statistics (\%). 


\begin{tabular}{|c|c|c|c|c|c|c|}
\hline Cities/Sub-areas & Abbrevations & Mean & Maximum & Minimum & $\mathrm{Sd}$ & nobs \\
\hline Helsinki-city & hki & 0.96 & 10.4 & -9.1 & 3.2 & 124 \\
\hline Helsinki-area1 & hki1 & 1.18 & 17.3 & -15.2 & 4.7 & 124 \\
\hline Helsinki-area2 & hki2 & 1.01 & 10.1 & -8.7 & 3.3 & 124 \\
\hline Helsinki-area3 & hki3 & 0.81 & 9.1 & -11.3 & 3.7 & 124 \\
\hline Helsinki-area4 & hki4 & 0.65 & 9.2 & -10.2 & 3.6 & 124 \\
\hline Tampere-city & tre & 0.88 & 10.0 & -8.8 & 3.1 & 124 \\
\hline Tampere-area1 & tre1 & 1.00 & 11.9 & -8.3 & 3.6 & 123 \\
\hline Tampere-area2 & tre2 & 0.75 & 9.9 & -16.8 & 4.5 & 123 \\
\hline Tampere-area3 & tre3 & 0.75 & 10.7 & -12.5 & 3.6 & 123 \\
\hline Turku-city & tku & 0.79 & 11.0 & -8.7 & 3.4 & 124 \\
\hline Turku-area1 & tku1 & 0.93 & 11.9 & -12.4 & 4.1 & 124 \\
\hline Turku-area2 & tku2 & 0.70 & 9.9 & -13.0 & 4.6 & 124 \\
\hline Turku-area3 & tku3 & 0.66 & 13.5 & -8.7 & 4.7 & 124 \\
\hline Oulu-city & oulu & 0.65 & 8.8 & -6.4 & 3.1 & 124 \\
\hline Oulu-area1 & oulu1 & 0.67 & 10.7 & -7.1 & 3.5 & 124 \\
\hline Oulu-area2 & oulu2 & 0.58 & 11.3 & -10.3 & 4.2 & 124 \\
\hline Lahti-city & lti & 0.52 & 10.4 & -8.8 & 3.4 & 124 \\
\hline Lahti-area1 & lti1 & 0.68 & 12.4 & -11.4 & 4.5 & 124 \\
\hline Lahti-area2 & lti2 & 0.34 & 11.2 & -7.7 & 3.9 & 124 \\
\hline Jyväskylä-city & jkla & 0.61 & 9.0 & -8.9 & 3.3 & 124 \\
\hline Jyväskylä-area1 & jkla1 & 0.71 & 11.7 & -10.1 & 3.8 & 124 \\
\hline Jyväskylä-area2 & jkla2 & 0.44 & 18.6 & -20.6 & 4.7 & 124 \\
\hline Pori-city & pori & 0.72 & 20.3 & -16.8 & 5.2 & 124 \\
\hline Pori-area1 & pori1 & 0.76 & 22.0 & -19.1 & 6.3 & 124 \\
\hline Pori-area2 & pori2 & 0.64 & 16.9 & -17.3 & 6.3 & 122 \\
\hline Kuopio-city & kuo & 0.69 & 12.1 & -13.1 & 3.5 & 124 \\
\hline Kuopio-area1 & kuo1 & 0.84 & 15.4 & -16.9 & 4.8 & 123 \\
\hline Kuopio-area2 & kuo2 & 0.53 & 10.9 & -9.7 & 3.7 & 124 \\
\hline Joensuu-city & jnsu & 0.64 & 13.8 & -12.6 & 4.9 & 124 \\
\hline Joensuu-area1 & jnsu1 & 0.64 & 15.5 & -13.7 & 5.6 & 124 \\
\hline Seinajöki-city & seoki & 0.70 & 18.9 & -15.6 & 5.9 & 118 \\
\hline Vaasa-city & vaasa & 0.70 & 9.6 & -9.0 & 4.0 & 123 \\
\hline Vaasa-area1 & vaasa1 & 0.78 & 9.8 & -9.8 & 4.3 & 121 \\
\hline Kouvoula-city & kou & 0.27 & 23.9 & -19.9 & 5.5 & 124 \\
\hline Lappeenranta-city & lrta & 0.52 & 14.9 & -11.5 & 3.9 & 124 \\
\hline Lappeenranta-area1 & lrta1 & 0.57 & 19.1 & -17.1 & 5.4 & 123 \\
\hline Lappeenranta-area2 & $\operatorname{lrta} 2$ & 0.46 & 18.9 & -19.8 & 5.7 & 122 \\
\hline Hämeenlinna-city & hnlina & 0.63 & 11.4 & -15.6 & 4.5 & 124 \\
\hline Hämeenlinna-area1 & hnlina1 & 0.62 & 13.1 & -18.4 & 5.2 & 124 \\
\hline Kotka-city & kotka & 0.58 & 13.2 & -11.0 & 5.0 & 124 \\
\hline Kotka-area1 & kotka1 & 0.70 & 16.7 & -17.5 & 6.3 & 121 \\
\hline Kotka-area2 & kotka2 & 0.52 & 19.4 & -27.0 & 8.1 & 96 \\
\hline
\end{tabular}

Notes: This table presents summary statistics on the two-rooms flats price index returns. Units are quarterly returns in percentage points. The sample is 1988:Q1 to 2018:Q4.

Table 2: Two-rooms flats quarterly house price returns - Summary statistics (\%). 


\begin{tabular}{|c|c|c|c|c|c|c|}
\hline Cities/Sub-areas & Abbrevations & Mean & Maximum & Minimum & $\mathrm{Sd}$ & nobs \\
\hline Helsinki-city & hki & 0.94 & 12.2 & -10.2 & 3.6 & 124 \\
\hline Helsinki-area1 & hki1 & 1.15 & 14.2 & -15.6 & 5.1 & 124 \\
\hline Helsinki-area2 & hki2 & 0.95 & 13.0 & -8.9 & 3.7 & 124 \\
\hline Helsinki-area3 & hki3 & 0.75 & 11.7 & -9.5 & 3.9 & 124 \\
\hline Helsinki-area4 & hki4 & 0.65 & 11.9 & -11.8 & 3.8 & 124 \\
\hline Tampere-city & tre & 0.87 & 11.0 & -12.4 & 3.7 & 123 \\
\hline Tampere-area1 & tre1 & 0.98 & 14.0 & -15.8 & 4.7 & 123 \\
\hline Tampere-area2 & tre2 & 0.91 & 11.7 & -15.3 & 5.5 & 116 \\
\hline Tampere-area3 & tre3 & 0.66 & 12.5 & -12.8 & 3.5 & 123 \\
\hline Turku-city & tku & 0.77 & 12.6 & -10.8 & 3.9 & 124 \\
\hline Turku-area1 & tku1 & 0.93 & 15.5 & -17.2 & 5.3 & 124 \\
\hline Turku-area2 & tku2 & 0.71 & 15.3 & -16.0 & 4.9 & 124 \\
\hline Turku-area3 & tku3 & 0.66 & 11.8 & -11.1 & 4.5 & 124 \\
\hline Oulu-city & oulu & 0.70 & 12.3 & -11.0 & 3.7 & 124 \\
\hline Oulu-area1 & oulu1 & 0.70 & 14.2 & -15.7 & 4.6 & 123 \\
\hline Oulu-area2 & oulu2 & 0.70 & 10.1 & -14.4 & 4.5 & 123 \\
\hline Lahti-city & lti & 0.56 & 11.6 & -12.2 & 4.4 & 124 \\
\hline Lahti-area1 & lti1 & 0.68 & 15.7 & -14.9 & 5.6 & 124 \\
\hline Lahti-area2 & lti2 & 0.41 & 10.1 & -11.7 & 4.5 & 124 \\
\hline Jyväskylä-city & jkla & 0.62 & 14.1 & -9.8 & 4.4 & 124 \\
\hline Jyväskylä-area1 & jkla1 & 0.66 & 15.7 & -12.9 & 5.0 & 122 \\
\hline Jyväskylä-area2 & jkla2 & 0.59 & 17.9 & -19.1 & 6.3 & 122 \\
\hline Pori-city & pori & 0.72 & 15.3 & -18.3 & 5.8 & 124 \\
\hline Pori-area1 & pori1 & 0.80 & 16.7 & -20.2 & 6.6 & 116 \\
\hline Kuopio-city & kuo & 0.59 & 13.6 & -15.7 & 4.4 & 124 \\
\hline Kuopio-area1 & kuo1 & 0.74 & 15.2 & -32.7 & 7.1 & 115 \\
\hline Kuopio-area2 & kuo2 & 0.49 & 15.4 & -20.5 & 4.9 & 122 \\
\hline Joensuu-city & jnsu & 0.66 & 17.6 & -20.1 & 6.2 & 124 \\
\hline Joensuu-area1 & jnsu1 & 0.72 & 20.4 & -22.0 & 7.2 & 108 \\
\hline Seinajöki-city & seoki & 0.80 & 24.3 & -27.7 & 7.2 & 103 \\
\hline Vaasa-city & vaasa & 0.68 & 14.7 & -16.7 & 5.1 & 123 \\
\hline Vaasa-area1 & vaasa1 & 0.79 & 17.5 & -14.9 & 5.9 & 116 \\
\hline Vaasa-area2 & vaasa2 & 0.84 & 13.8 & -22.9 & 7.0 & 82 \\
\hline Kouvoula-city & kou & 0.14 & 14.1 & -15.0 & 6.7 & 121 \\
\hline Lappeenranta-city & lrta & 0.45 & 11.9 & -17.1 & 5.5 & 121 \\
\hline Lappeenranta-area2 & $\operatorname{lrta} 2$ & 0.89 & 21.2 & -25.1 & 7.0 & 80 \\
\hline Hämeenlinna-city & hnlina & 0.61 & 19.9 & -17.1 & 6.1 & 122 \\
\hline Hämeenlinna-area1 & hnlina1 & 0.70 & 24.3 & -17.7 & 7.3 & 108 \\
\hline Kotka-city & kotka & 0.49 & 19.6 & -19.2 & 6.4 & 120 \\
\hline
\end{tabular}

Notes: This table presents summary statistics on the more than three rooms flats price index returns. Units are quarterly returns in percentage points. The sample is 1988:Q1 to 2018:Q4.

Table 3: More than three rooms flats quarterly house price returns - Summary statistics $(\%)$. 


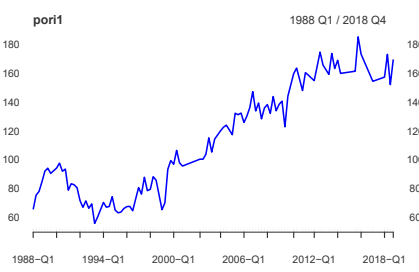

(a)

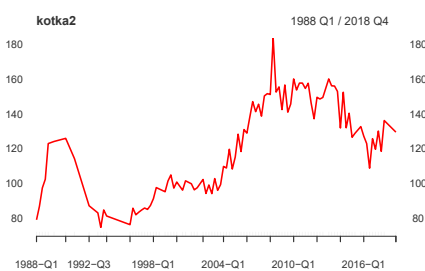

(d)

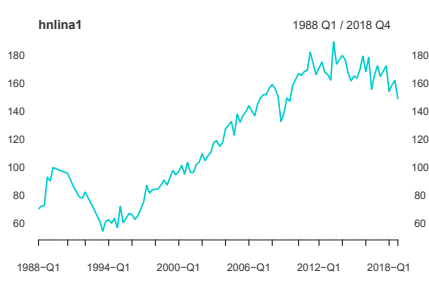

(g)

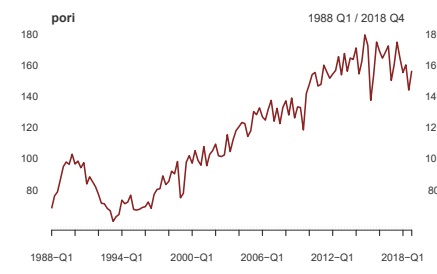

(b)

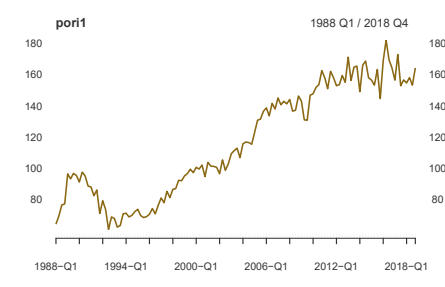

(e)

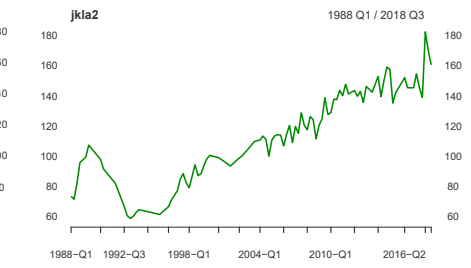

(c)

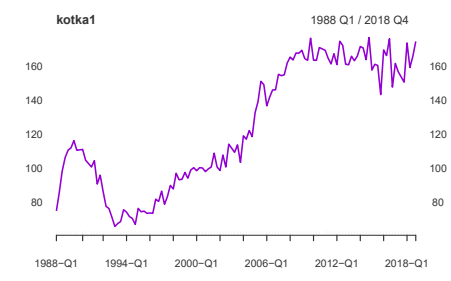

(f)

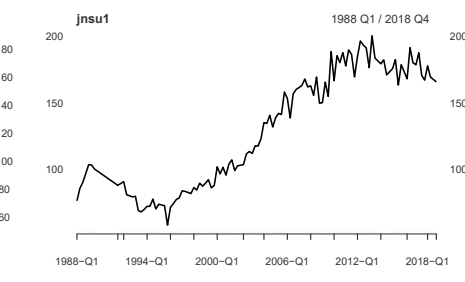

(h)

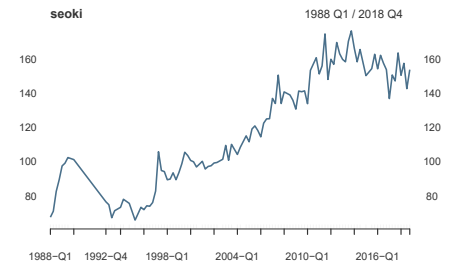

(i)

Figure 1: The house price movement of the most volatile cities/sub-areas.

\section{Methodology}

The methodology employed in this study is presented as follows: first, we define returns as log differences of the price indices in percentages (multiplied by 100) for each city and subarea in each of the apartment type. Thereafter we filter first order autocorrelations from the returns with an ARMA model of appropriate order determined by Akaike information criteria (AIC) and Bayesian information criteria (BIC). Next, we test ARCH effects on the ARMA filtered returns. Then, for cities and sub-areas with significant clustering effects, individual GARCH models are used to model the nature of the time-varying volatility. Moreover, GARCH-in-mean (GARCH-M) model is employed to investigate the relationship between housing returns and volatility. Lastly, the Exponential GARCH (EGARCH) model is used to analyse the asymmetric effects of the shocks. Although the Glosten, Jagannthan, and Runkle GARCH (GJR-GARCH) model was also employed; the EGARCH proved to be effective in modelling the studied house prices. All analysis was conducted in $R$ (R Core Team, 2019).

\section{Testing for ARCH effects}

After filtering serial correlations from the returns series, the squared residual series are used to check the autoregressive conditional heteroscedasticity, also known as ARCH effects. If the null hypothesis of constant variance is rejected, then volatility modelling is required. 
Two tests are available. The first test, called Portmanteau $Q(m)$, is to examine whether the squares of the residuals are a sequence of white noise. It is the usual Ljung-Box test on the squared residuals (see Mcleod and Li, 1983). The null hypothesis of the test statistic is that "there is no autocorrelation in the squared residuals up to lag $m$;" that is, the first $m$ lags of the autocorrelation function (ACF) of the squared residuals are zeros. A small $\mathrm{p}$-value (smaller than the considered critical value) suggests the presence of autoregressive conditional heteroscedasticity (strong ARCH effects).

The second test is the Lagrange Multiplier test of Engle (1982), also known as ARCH-LM Engle's test. This test is to fit a linear regression model for the squared residuals and examine that the fitted model is significant. It is equivalent to the usual $F$ statistic for testing $\gamma_{i}=0(i=1, \ldots, m)$ in the linear regression

$$
\hat{e}_{t}^{2}=\gamma_{0}+\gamma_{1} \hat{e}_{t-1}^{2}+\ldots+\gamma_{m} \hat{e}_{t-m}^{2}+v_{t}, \quad t=m+1, \ldots N
$$

where $\hat{e}_{t}^{2}$ is the estimated residuals, $v_{t}$ is the random error, $m$ is a prespecified positive integer, and $N$ is the sample size. The null hypothesis of the test is that "there are no ARCH effects;" that is, $H_{0}: \gamma_{1}=\ldots .=\gamma_{m}=0$, and the alternative hypothesis is $H_{1}: \gamma_{i} \neq 0$ (there are ARCH effects). Again, the null hypothesis is rejected if a $\mathrm{p}-$ value smaller than the considered critical value is obtained at the specified number of lags. The ARCH-LM tests were performed using the function ArchTest() from the FinTs package (Graves, 2019).

\section{Volatility modelling}

The dynamics of the time--varying conditional variance of the house price returns of those cities and sub-areas with significant ARCH effects are analysed using the Generalized Autoregressive Conditional Heteroscedasticity (GARCH)-type models.

Let $R_{t}$ be the log-return of an asset at time $t$. The conditional volatility model is of the following form:

$$
\begin{gathered}
R_{t}=u_{t}+e_{t}, \quad e_{t} \sim \mathcal{N}\left(0, \sigma_{t}^{2}\right), \\
\sigma_{t}^{2}=\omega+\alpha_{1} e_{t-1}^{2}+\alpha_{2} e_{t-2}^{2}+\ldots+\alpha_{q} e_{t-q}^{2},
\end{gathered}
$$

where $u_{t}$ is the conditional mean, $\sigma_{t}$ is the conditional standard deviation, $e_{t}$ is the error term, and $\omega>0$ is the intercept.

In the GARCH model proposed by Bollerslev (1986), the conditional variance $\sigma_{t}^{2}$ depends on previous squared errors and past volatility. That is,

$$
\sigma_{t}^{2}=\omega+\sum_{i=1}^{q} \alpha_{i} e_{t-i}^{2}+\sum_{j=1}^{p} \beta_{j} \sigma_{t-j}^{2},
$$

where $\alpha_{i} \geq 0$ (coefficients of $e_{t-i}$ ) are referred to as the ARCH parameters and $\beta_{j} \geq 0$ (coefficients of $\sigma_{t-j}^{2}$ ) as the GARCH parameters.

It is worth mentioning that it is not plausible to assume a normal distribution when analysing asset returns with GARCH-type models. A realistic distribution needs to accommodate asset returns characteristics such as fat tails and skewness. Thus, univariate distributions such as Generalized Error ('GED'), Student $t$ ('Std'), and their skew variants ('sGED', 'sStd') can be used. For more details, see Tsay (2013).

The estimation of individual GARCH models were performed using the rugarch package (Ghalanos, 2019), and followed the following steps:

- Model specification by ugarchspec() function, 
- Model estimation by ugarchfit() function,

- Model adequacy checking using the standardised residuals tests.

Regarding the distribution of the error term $\left(e_{t}\right)$ for each city and sub-area; based on Akaike information criteria (AIC) and Bayesian information criteria (BIC), the selected distributions are as follows:

- In the one-room flats category, nine cities/sub-areas follow a normal distribution. Four follow a Generalized Error Distribution ("GED"). Three follow a Student $t$ distribution ("Std"). Eleven follow a skew normal distribution ("snorm"), and one follows a skew Generalized Error Distribution ("sGED").

- In the two-rooms flats category, fourteen cities/sub-areas follow a normal distribution. Three follow a GED; six follow a snorm; three follow a sGED, and one follows a skew Student $t$ distribution ("sStd").

- In the more than three rooms flats category, eighteen cities/sub-areas follow a normal distribution. Four follows a GED; three follow a Std; five follow a snorm, and one follows a sGED.

\section{Testing for GARCH-M effects}

In addition to testing and estimating GARCH models, and for modelling and forecasting purposes; there are other crucial volatility issues to note, that GARCH models are employed to investigate. One is the determination of the potential impact that the conditional variance may have on returns. This phenomenon was initially pointed out by Engle et al. (1987); the authors developed an innovation GARCH model known as GARCH-in-mean (GARCH-M) model and applied to the Treasury bond returns.

The model setup consists of specifying the conditional mean as a linear function of the conditional variance. That is,

$$
\begin{gathered}
R_{t}=u_{t}+\lambda \sigma_{t}^{2}+e_{t}, \quad e_{t} \sim \mathcal{N}\left(0, \sigma_{t}^{2}\right), \\
\sigma_{t}^{2}=\omega+\sum_{i=1}^{q} \alpha_{i} e_{t-i}^{2}+\sum_{j=1}^{p} \beta_{j} \sigma_{t-j}^{2},
\end{gathered}
$$

where the parameter $\lambda$ describes the nature of the relationship between asset return and volatility. A significant positive $\lambda$ implies that the asset return is positively related to its volatility. In other words, an increased risk leads to an increased mean return. This technique has been applied to other asset markets, such as stocks and equities. However, even though intuitively a positive $\lambda$ is expected; studies such as Glosten et al. (1993) highlighted reasons that could indicate a negative $\lambda$, as there is no theoretical restriction on the sign of $\lambda$. Thus, different signs of $\lambda$ have been documented in different markets. In the housing market, the GARCH-M model has been applied by Milles (2008) to the US market and Milles (2011b) to the UK market; mixed results of positive and negative riskreturn impact were found across the studied areas. Following these studies, this article employs the GARCH-M model to investigate the relationship between housing returns and volatility in the Finnish market. Moreover, an individual estimation is done on each city and sub-area to allow the impact of volatility on returns to differ from region to region and by apartment type. 


\section{Testing for Asymmetric volatility}

Another issue in GARCH modelling is the presence of asymmetric volatility. That is the possibility of asymmetric effects of shocks on conditional variance. An observation that a negative return gives rise to subsequent volatility than a positive return is termed the leverage effect; while the contradicting observation, the volatility feedback effect is based on the observed positive correlations between asset volatility and returns. Two GARCH models are mostly used to examine these effects; those are the Glosten, Jagannthan, and Runkle GARCH (GJR-GARCH) model by Glosten et al. (1993) and the Exponential GARCH (EGARCH) model by Nelson (1991).

The former model allows negative shocks to have a different effect on volatility than positive shocks, and it is specified as follows:

$$
\begin{gathered}
R_{t}=u_{t}+e_{t}, \quad e_{t} \sim \mathcal{N}\left(0, \sigma_{t}^{2}\right), \\
\sigma_{t}^{2}=\omega+\sum_{i=1}^{q}\left(\alpha_{i}+\gamma_{i} I_{t-i}\right) e_{t-i}^{2}+\sum_{j=1}^{p} \beta_{j} \sigma_{t-j}^{2},
\end{gathered}
$$

where $\alpha_{i}$ and $\alpha_{i}+\gamma_{i}$ represent the impact of good news and bad news respectively, and the indicator function $I_{t-i}$ is equal to one if $e_{t-1}<0$ and zero otherwise. That is, a negative shock $e_{t-i}$ has a more significant impact $\left(\alpha_{i}+\gamma_{i}\right) e_{t-i}^{2}$ with $\gamma_{i}>0$, whereas a positive shock $e_{t-i}$ have less effect $\alpha_{i} e_{t-i}^{2}$ to $\sigma_{t}^{2}$. An estimated $\gamma \neq 0$ implies asymmetry, and leverage effects exist if $\gamma>0$, meaning that if $\gamma$ is positive significant, negative innovations affect volatility than positive shocks.

The latter model applies the logged conditional variance so that the volatility is always positive. Its specification is as follows:

$$
\begin{gathered}
R_{t}=u_{t}+e_{t}, \quad e_{t} \sim \mathcal{N}\left(0, \sigma_{t}^{2}\right), \\
\log \left(\sigma_{t}^{2}\right)=\omega+\sum_{i=1}^{q}\left(\alpha_{i}\left|z_{t-i}\right|+\gamma_{i} z_{t-i}\right)+\sum_{j=1}^{p} \beta_{j} \log \sigma_{t-j}^{2},
\end{gathered}
$$

where $z_{t}=e_{t} / \sqrt{\sigma_{t}^{2}}$ is the standardized shock. Again, $\gamma \neq 0$ implies an asymmetric impact. However, leverage effect exist if $\gamma<0$; following Black (1976)'s argument that negative shocks have more effect on the rise of the conditional volatility than positive innovations of equal magnitude.

In the housing market, both GJR-GARCH and EGARCH models have been employed in different markets to investigate asymmetric volatility. The GJR-GARCH model has been used by Milles (2008) in the US; Tsai and Chen (2009) and Milles (2011b) in the UK market. The EGARCH model which is the widely used one has been employed by Morley and Thomas (2011) in the UK; Lee (2009) in Australian; and Lin and Fuerst (2014) in the Canadian market. The reason behind the acknowledgement of the EGARCH model is the evidence of its good performance in stock and real estate markets provided by Engle and Ng (1993) and Stevenson (2002). More recently Katsiampa and Begiazi (2019) applied both models on the Scottish housing market. To that end, and for models' estimation comparison purposes; this study also employs both GJR-GARCH and EGARCH models to examine the presence of asymmetric volatility in the Finnish housing market. Same as the above-cited studies, the EGARCH model proved to be effective in modelling the studied house prices; confirming once more its good performance (GJR-GARCH model's results available from the author upon request). Again, an individual estimation is done for each city and sub-area in each apartment type to allow different effects. Following Lee 
(2009), high-order models are compared to the EGARCH(1,1) model using Akaike information criteria (AIC) and Bayesian information criteria (BIC) to determine the optimal specification for an EGARCH model for each city and sub-area.

\section{Results and discussions}

\section{Testing for ARCH effects}

Tables 4 and 5 display the p-values of the two tests employed to investigate whether there is volatility clustering in each housing return series. Those tests are the Ljung-Box (LB) test and the Engle's Lagrange Multiplier (LM) test. The null hypothesizes of no serial correlation in squared residuals and no ARCH effects, of the LB test and LM test respectively are rejected in twenty-eight out of thirty-eight studied cities and sub-areas in the one-room flats category; in twenty-seven out forty-two in the two-rooms flats category; and in thirty-one out of thirty-nine in the more than three rooms flats category. Thus, strong evidence of volatility clustering $(\mathrm{ARCH})$ effects is evident in over half of the cities and sub-areas in all three apartments types; suggesting that the Finnish house price volatility contains critical information that should be addressed by housing investors, buyers, and policymakers to assess the risk of housing investment.

In some cases, one of the tests is inconclusive, for instance, in the case of Tampere-area1 (in the one-room flats category) and Turku-area2 (in the two-rooms flats category), the Ljung-Box test is inconclusive (we fail to reject the null hypothesis because of the higher p-values); however, the Lagrange Multiplier values are statistically significant. Similarly, in the case of Lahti-area1 (in the more than three rooms flats category), this time, however, it is the Lagrange Multiplier test, which is inconclusive. In these cases, the autocorrelation function $(\mathrm{ACF})$ and partial autocorrelation function $(\mathrm{PACF})$ plots of the squared residuals (figures available from the author upon request) may be used to demonstrate that there might be some autocorrelations left even though the significance might be low.

The evidence of the volatility clustering effect found in this study is stronger compared to other housing markets such as the US and the UK, where Milles (2008) and Milles (2011b) respectively documented less significant ARCH effects. More precisely, twentyeight out of fifty US states and seven out of twelve UK regions were found to exhibit $\mathrm{ARCH}$ effects. Strong ARCH effects were also found in the Australian housing market by Lee (2017), where all the studied cities displayed time-varying volatility; however, this strong effect was attributed to the use of higher frequency data (daily data), while other studies employed quarterly or monthly data. Moreover, we found a little pattern to which cities and sub-areas had ARCH effects and which did not. Regions such us Ouluarea2, Lahti-area2, and Joensuu-city lack volatility clustering in all three apartment types, while no clustering effects were discovered in Tampere-city and Vaasa-area1 in both oneroom and two-rooms apartment types. Furthermore, densely populated regions such as Helsinki as well as thinly populated cities such as Kotka were found to exhibit volatility clustering effects. An observation which is, on the one hand, in contrast with Lin and Fuerst's (2014) claim that the density of the population in the region may be the source of volatility clustering. On the other hand, our results are consistent with Lee's (2017) analysis outcome, who found significant ARCH effects even in small Australian cities such as Adelaide. Therefore, the identification of possible sources of volatility is the subject of further research.

In summary, ARCH effects discovered in different cities and sub-areas in all three apartment types, suggest that a housing portfolio concentrated in one or several regions 
may be risky; however, diversifying a portfolio across Finland and by apartment type can lower risk. This finding is important as many investors are often highly concentrated in narrow geographical regions such as Helsinki.

\begin{tabular}{|c|c|c|c|c|c|c|c|c|c|}
\hline \multirow[b]{2}{*}{ Regions } & & \multicolumn{4}{|c|}{ One room flats } & \multicolumn{4}{|c|}{ Two rooms flats } \\
\hline & Cities/sub-areas & ARMA & LB & LM & ARCH? & ARMA & LB & LM & $\mathrm{ARCH} ?$ \\
\hline \multirow{5}{*}{ Helsinki } & hki & $\operatorname{ARMA}(2,1)$ & $0.0204^{* *}$ & $0.0221^{* *}$ & yes & $\operatorname{ARMA}(2,1)$ & $0.0004^{* * *}$ & $0.0005^{\text {*** }}$ & yes \\
\hline & hki1 & $\mathrm{MA}(2)$ & $0.0296^{* *}$ & $0.0317^{* *}$ & yes & $\operatorname{ARMA}(2,1)$ & $0.0443^{* *}$ & $0.0186^{* *}$ & yes \\
\hline & hki2 & $\operatorname{ARMA}(2,1)$ & $0.0162^{* *}$ & $0.0193^{* *}$ & yes & $\mathrm{AR}(1)$ & $0.0025^{* *}$ & $0.0029^{* *}$ & yes \\
\hline & hki3 & $\operatorname{ARMA}(2,1)$ & 0.5206 & 0.4721 & no & $\mathrm{AR}(2)$ & $0.0256^{* *}$ & $0.0319^{* *}$ & yes \\
\hline & hki4 & $\mathrm{AR}(2)$ & $0.0255^{* *}$ & $0.0305^{* *}$ & yes & $\operatorname{ARMA}(1,1)$ & $0.0921^{*}$ & $0.0905^{*}$ & yes \\
\hline \multirow{4}{*}{ Tampere } & tre & $\operatorname{ARMA}(1,1)$ & 0.3557 & 0.8176 & no & $\operatorname{ARMA}(2,1)$ & 0.829 & 0.831 & no \\
\hline & tre1 & $\operatorname{ARMA}(2,2)$ & 0.4351 & $0.0105^{* *}$ & yes & $\operatorname{AR}(2)$ & $0.0315^{* *}$ & $0.0752^{*}$ & yes \\
\hline & tre2 & $\operatorname{ARMA}(1,1)$ & 0.978 & 0.7062 & no & $\operatorname{ARMA}(0,0)$ & $0.0051^{* *}$ & $0.0108^{* *}$ & yes \\
\hline & tre3 & $\mathrm{AR}(2)$ & $0.0913^{*}$ & $0.0258^{* *}$ & yes & $\operatorname{ARMA}(2,2)$ & 0.2858 & 0.2683 & no \\
\hline \multirow{4}{*}{ Turku } & tku & $\operatorname{ARMA}(2,2)$ & $0.0039^{* *}$ & $0.0126^{* *}$ & yes & $\operatorname{ARMA}(2,2)$ & $0.0432^{* *}$ & $0.0494^{* *}$ & yes \\
\hline & tku1 & $\operatorname{ARMA}(1,1)$ & $0.0369^{* *}$ & $0.0179^{* *}$ & yes & $\mathrm{AR}(2)$ & 0.5196 & 0.5257 & no \\
\hline & tku2 & $\operatorname{AR}(1)$ & $0.0635^{*}$ & $0.0681^{*}$ & yes & $\operatorname{ARMA}(0,0)$ & 0.2146 & $0.0997^{*}$ & yes \\
\hline & tku3 & $\operatorname{AR}(1)$ & 0.2593 & $0.0019 * *$ & yes & $\mathrm{MA}(3)$ & 0.1846 & 0.187 & no \\
\hline \multirow{3}{*}{ Oulu } & oulu & $\operatorname{ARMA}(1,1)$ & $0.0116^{* *}$ & $0.0111^{* *}$ & yes & $\operatorname{AR}(2)$ & 0.333 & 0.3378 & no \\
\hline & oulu1 & $\mathrm{AR}(1)$ & $0.0716^{*}$ & $0.0754^{*}$ & yes & $\operatorname{ARMA}(1,2)$ & 0.5143 & 0.5191 & no \\
\hline & oulu2 & $\operatorname{AR}(1)$ & 0.1065 & 0.1049 & no & $\operatorname{ARMA}(0,0)$ & 0.1008 & 0.7517 & no \\
\hline \multirow{3}{*}{ Lahti } & lti & $\mathrm{AR}(2)$ & $0.0092^{* *}$ & $0.0099 * *$ & yes & $\mathrm{AR}(2)$ & $0.0882^{*}$ & $0.0881^{*}$ & yes \\
\hline & lti1 & $\operatorname{AR}(1)$ & $0.0026^{* *}$ & $0.0031 * *$ & yes & $\mathrm{AR}(2)$ & 0.5808 & 0.5838 & no \\
\hline & lti2 & $\operatorname{AR}(1)$ & 0.6409 & 0.5526 & no & $\operatorname{ARMA}(1,2)$ & 0.989 & 0.9995 & no \\
\hline \multirow{3}{*}{ Jyväskylä } & jkla & $\operatorname{ARMA}(1,1)$ & $0.0296^{* *}$ & $0.0111^{* *}$ & yes & $\operatorname{ARMA}(2,2)$ & $0.0108^{* *}$ & $0.007^{* *}$ & yes \\
\hline & jkla1 & $\operatorname{ARMA}(1,1)$ & $0.0255^{* *}$ & $0.0075^{* *}$ & yes & $\mathrm{MA}(3)$ & $0.0123^{* *}$ & $0.0125^{* *}$ & yes \\
\hline & jkla2 & $\operatorname{ARMA}(0,0)$ & 0.3453 & $0.0326^{* *}$ & yes & $\operatorname{ARMA}(1,2)$ & $1.22 * 10^{-5 * * *}$ & $1.43 * 10^{-5 * * *}$ & yes \\
\hline \multirow{3}{*}{ Pori } & pori & $\mathrm{MA}(1)$ & $0.0257^{* *}$ & $0.0323^{* *}$ & yes & $\mathrm{MA}(3)$ & $0.0027^{* *}$ & $0.0017^{* *}$ & yes \\
\hline & pori1 & $\mathrm{AR}(2)$ & $0.0522^{*}$ & $0.0699^{*}$ & yes & $\mathrm{MA}(3)$ & $0.0124^{* *}$ & $0.0126^{* *}$ & yes \\
\hline & pori2 & & - & - & - & $\operatorname{ARMA}(2,2)$ & $0.0568^{*}$ & $0.0589^{*}$ & yes \\
\hline \multirow{3}{*}{ Kuopio } & kuo & $\operatorname{ARMA}(0,0)$ & $0.0324^{* *}$ & $0.0305 * *$ & yes & $\mathrm{AR}(2)$ & $0.0224^{* *}$ & $0.0195^{* *}$ & yes \\
\hline & kuo1 & $\mathrm{MA}(2)$ & $0.0842^{*}$ & $0.0891 *$ & yes & $\operatorname{ARMA}(0,0)$ & $0.0030^{* *}$ & $0.0017^{* *}$ & yes \\
\hline & kuo2 & $\operatorname{ARMA}(0,0)$ & $0.0167^{* *}$ & $0.0191 * *$ & yes & $\operatorname{AR}(2)$ & 0.6987 & 0.69 & no \\
\hline \multirow{2}{*}{ Joensuu } & jnsu & $\mathrm{MA}(3)$ & 0.9751 & 0.961 & no & $\operatorname{AR}(3)$ & 0.3522 & 0.3578 & no \\
\hline & jnsu1 & $\mathrm{MA}(3)$ & $0.0502^{* *}$ & $0.0457^{* *}$ & yes & $\operatorname{AR}(3)$ & $0.0424^{* *}$ & 0.1197 & yes \\
\hline \multirow[t]{2}{*}{ Seinäjoki } & seoki & - & - & - & - & $\operatorname{AR}(1)$ & $0.0109^{* *}$ & $0.0103^{* *}$ & yes \\
\hline & vaasa & $\mathrm{MA}(1)$ & 0.8133 & 0.8154 & no & $\operatorname{ARMA}(1,2)$ & $0.0634^{*}$ & $0.0668^{*}$ & yes \\
\hline Vaasa & vaasa1 & $\mathrm{MA}(1)$ & 0.9039 & 0.9057 & no & $\mathrm{MA}(2)$ & 0.3136 & 0.3199 & no \\
\hline \multirow[t]{2}{*}{ Kouvola } & kou & $\operatorname{AR}(1)$ & $0.0161^{* *}$ & $0.0105^{* *}$ & yes & $\operatorname{ARMA}(1,2)$ & $0.0012^{* *}$ & $0.0013^{* *}$ & yes \\
\hline & lrta & $\operatorname{AR}(1)$ & $0.0548^{*}$ & $0.0581^{*}$ & yes & $\mathrm{MA}(3)$ & $0.0009^{* * *}$ & $0.0011^{* *}$ & yes \\
\hline \multirow[t]{2}{*}{ Lappeenranta } & lrtal & MA(1) & $0.0086^{* *}$ & $0.0361 * *$ & yes & $\operatorname{ARMA}(2,2)$ & $0.0021^{* *}$ & $0.0025^{* *}$ & yes \\
\hline & lrta2 & - & & - & - & $\operatorname{AR}(1)$ & 0.9971 & 0.997 & no \\
\hline \multirow{2}{*}{ Hämeenlinna } & hnlina & $\mathrm{MA}(3)$ & $0.0032^{* *}$ & $0.0038^{* *}$ & yes & $\operatorname{ARMA}(0,0)$ & $0.0703^{*}$ & $0.0700^{*}$ & yes \\
\hline & hnlina1 & $\mathrm{MA}(3)$ & 0.8936 & 0.8955 & no & $\operatorname{ARMA}(1,2)$ & $0.0168^{* *}$ & $0.0166^{* *}$ & yes \\
\hline \multirow{3}{*}{ Kotka } & kotka & MA(1) & $0.0304^{* *}$ & $0.0244^{* *}$ & yes & $\mathrm{MA}(3)$ & 0.1588 & 0.1269 & no \\
\hline & kotka1 & $\mathrm{MA}(3)$ & 0.8673 & 0.8621 & no & $\mathrm{MA}(2)$ & 0.5307 & $0.0577^{*}$ & yes \\
\hline & kotka2 & - & - & - & - & $\mathrm{MA}(2)$ & 0.1854 & 0.194 & no \\
\hline
\end{tabular}

Notes: This table reports the ARMA model for each city and sub-area, and the p-values from the Ljung-Box and Lagrange Multiplier tests. *, **, and *** represent respectively $10 \%, 5 \%$, and $1 \%$ levels of significance. "yes" indicates that a city/sub-area exhibits ARCH effects, "no" means that a city/sub-area does not.

Table 4: ARCH effects tests results. 


\begin{tabular}{|c|c|c|c|c|c|}
\hline \multirow[b]{2}{*}{ Regions } & & \multicolumn{4}{|c|}{ Three rooms flats } \\
\hline & Cities/sub-areas & ARMA & LB & LM & ARCH? \\
\hline \multirow{5}{*}{ Helsinki } & hki & $\mathrm{AR}(1)$ & $0.0063^{* *}$ & $0.0037^{* *}$ & yes \\
\hline & hki1 & $\mathrm{AR}(2)$ & $0.0034^{* *}$ & $0.0038^{* *}$ & yes \\
\hline & hki2 & $\operatorname{AR}(1)$ & 0.6742 & 0.6784 & no \\
\hline & hki3 & $\operatorname{AR}(2)$ & $0.0079 * *$ & $0.0524^{*}$ & yes \\
\hline & hki4 & $\mathrm{AR}(2)$ & $0.0366^{* *}$ & $0.0382^{* *}$ & yes \\
\hline \multirow{4}{*}{ Tampere } & tre & $\operatorname{ARMA}(2,2)$ & $0.0386^{* *}$ & $0.0371^{* *}$ & yes \\
\hline & tre1 & $\operatorname{ARMA}(2,2)$ & $0.0346^{* *}$ & $0.0362 * *$ & yes \\
\hline & tre2 & $\operatorname{ARMA}(2,2)$ & $0.0301^{* *}$ & $0.0329 * *$ & yes \\
\hline & tre3 & $\operatorname{ARMA}(1,1)$ & 0.0911* & $0.0238^{* *}$ & yes \\
\hline \multirow{4}{*}{ Turku } & tku & $\operatorname{ARMA}(2,2)$ & $0.0255^{* *}$ & $0.0244^{* *}$ & yes \\
\hline & tku1 & $\mathrm{AR}(1)$ & $0.0596^{*}$ & $0.0599^{*}$ & yes \\
\hline & tku2 & $\operatorname{ARMA}(2,2)$ & $0.0784^{*}$ & $0.0825^{*}$ & yes \\
\hline & tku3 & $\operatorname{ARMA}(0,0)$ & $0.0009^{* * *}$ & $0.0011^{* *}$ & yes \\
\hline \multirow{3}{*}{ Oulu } & oulu & $\operatorname{ARMA}(1,2)$ & $0.0172^{* *}$ & $0.0249^{* *}$ & yes \\
\hline & oulu1 & $\operatorname{ARMA}(1,2)$ & $0.0465 * *$ & $0.0745^{*}$ & yes \\
\hline & oulu2 & $\mathrm{MA}(3)$ & 0.4018 & 0.407 & no \\
\hline \multirow{3}{*}{ Lahti } & lti & $\operatorname{ARMA}(2,2)$ & $0.0034^{* *}$ & $0.0034^{* *}$ & yes \\
\hline & lti1 & $\mathrm{MA}(3)$ & $0.0141 * *$ & 0.2274 & yes \\
\hline & lti2 & $\operatorname{ARMA}(2,2)$ & 0.9306 & 0.9865 & no \\
\hline \multirow{3}{*}{ Jyväskylä } & jkla & $\operatorname{ARMA}(1,2)$ & $0.0393^{* *}$ & $0.0423^{* *}$ & yes \\
\hline & jkla1 & $\operatorname{ARMA}(2,2)$ & $0.0369^{* *}$ & $0.0859^{*}$ & yes \\
\hline & jkla2 & $\operatorname{ARMA}(1,2)$ & $0.0199 * *$ & $0.0216^{* *}$ & yes \\
\hline \multirow{2}{*}{ Pori } & pori & $\operatorname{ARMA}(2,2)$ & 0.75 & 0.7537 & no \\
\hline & pori1 & $\mathrm{MA}(1)$ & $0.0312^{* *}$ & $0.0338^{* *}$ & yes \\
\hline \multirow{3}{*}{ Kuopio } & kuo & $\operatorname{ARMA}(0,0)$ & $3.25 * 10^{-5 * * *}$ & $3.72 * 10^{-5 * * *}$ & yes \\
\hline & kuo1 & $\mathrm{MA}(1)$ & $0.0506^{*}$ & $0.0544^{*}$ & yes \\
\hline & kuo2 & $\operatorname{ARMA}(1,2)$ & 0.9288 & $0.0023^{* *}$ & yes \\
\hline \multirow{2}{*}{ Joensuu } & jnsu & $\operatorname{AR}(1)$ & 0.7833 & 0.7856 & no \\
\hline & jnsu1 & $\operatorname{AR}(1)$ & 0.2663 & 0.3491 & no \\
\hline \multirow[t]{2}{*}{ Seinäjoki } & seoki & $\mathrm{MA}(3)$ & $0.0281^{* *}$ & $0.0130^{* *}$ & yes \\
\hline & vaasa & $\operatorname{ARMA}(1,2)$ & $0.0938^{*}$ & $0.0990^{*}$ & yes \\
\hline \multirow[t]{2}{*}{ Vaasa } & vaasa1 & $\mathrm{MA}(1)$ & $0.0156^{* *}$ & $0.0173^{* *}$ & yes \\
\hline & vaasa2 & $\operatorname{ARMA}(0,0)$ & $0.0038^{* *}$ & $0.0094^{* *}$ & yes \\
\hline Kouvola & kou & $\mathrm{MA}(3)$ & 0.8182 & 0.8207 & no \\
\hline \multirow{2}{*}{ Lappeenranta } & lrta & MA(3) & $0.0645^{*}$ & $0.0680^{*}$ & yes \\
\hline & lrta2 & $\operatorname{ARMA}(0,0)$ & $0.0004^{* * *}$ & $0.0006^{* * *}$ & yes \\
\hline \multirow{3}{*}{ Hämeenlinna } & hnlina & $\mathrm{MA}(3)$ & 0.9513 & 0.9519 & no \\
\hline & hnlina1 & $\operatorname{AR}(1)$ & $0.0031^{* *}$ & $0.0009^{* * *}$ & yes \\
\hline & kotka & ARMA $(2,2)$ & $0.0604^{*}$ & $0.0498^{*}$ & yes \\
\hline
\end{tabular}

Notes: This table reports the ARMA model for each city and sub-area, and the $\mathrm{p}$-values from the Ljung-Box and Lagrange Multiplier tests. ${ }^{*},{ }^{* *}$, and ${ }^{* * *}$ represent respectively $10 \%, 5 \%$, and $1 \%$ levels of significance. "yes" indicates that a city/sub-area exhibits ARCH effects, "no" means that a city/sub-area does not.

Table 5: ARCH effects tests results - Continued.

\section{Volatility modelling}

For cities and sub-areas displaying significant volatility clustering, the historical conditional volatility dynamic is investigated from individuals GARCH models, to allow different regions volatility behaviour, and analyse how these regions adjust to the financial shocks.

Based on the number of inhabitants, a sample of three cities/sub-areas over the studied period is drawn in each apartment category and shown in Figure 2. Those are Helsinki, Lahti, and Lappeenranta cities in the one-room flats category. Helsinki-area2, Vaasacity, and Kotka-area1 in the two-rooms flats category. Tampere-city, Kuopio-are2, and Hämeenlinna-area1 in the more than three rooms flats category. As it can be observed in almost all sample regions, the conditional variance was high at the end of the 1980s due to the housing boom that Finland experienced between 1987 and mid-1989; mainly as a result of the financial market deregulation which induces house prices to rise to more than 60 per cent (André and García, 2012). After the bursting of the housing bubble, the Finnish housing market experienced some downturns, upturns, and some steady trend 
in some regions until around mid-1993 where the extreme volatility swing is observed in almost all the cities/sub-areas especially in Lappeenranta and Vaasa. The moderate growth path noticed in the Finnish housing market in the 1990s is mainly due to the reformation of the state support for housing done around the same time; with the creation of the Housing Fund of Finland (ARA), and Finland's entry into the European Union which causes the drop of inflation (Kivistö, 2012). This moderate housing trend can be very well observed in all three samples from the more than three rooms apartment type after the year 1995; meaning that the house prices of this flat category have been somehow steady, no extremely volatility swings.

An increase in conditional volatility is observed during the Global Financial Crisis from 2007 to 2008; however, the adjustment to such financial shock differed across city and subarea market. In the Helsinki and Lahti city, the highest housing volatility occurred in 2008, while in Lappeenranta-city, it began in 2007. In Vaasa-city, the most significant swing was observed in 2009. For Lahti-city and Kotka-area1, the peak level of conditional volatility is at the end of the sample around the year 2016-2017.

$H$ e Is in $k i-c$ it y C o n d it ion a I Volatility

[ $\left.\begin{array}{lllllllllllllll}1 & 9 & 8 & 8 & : 0 & 1 & \text { t } & 0 & 2 & 0 & 1 & 8 & : 0 & 4\end{array}\right]$

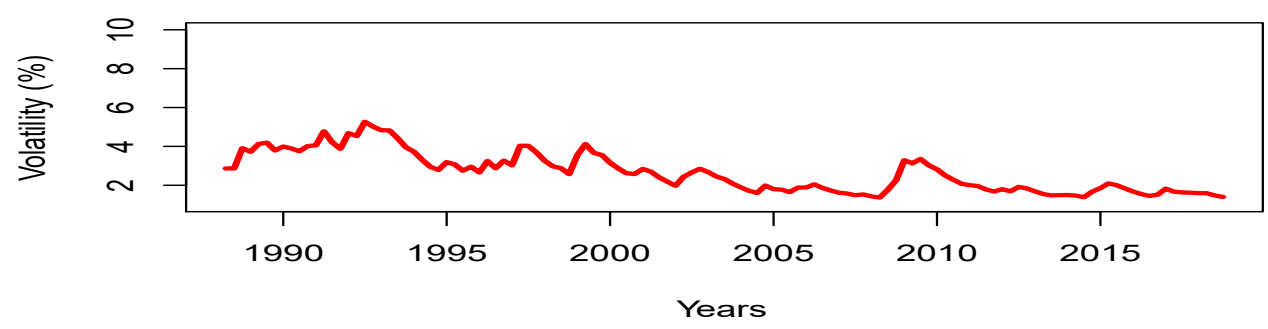

Lahti-city Conditional Volatility [1988:Q1 to 2018:Q4]

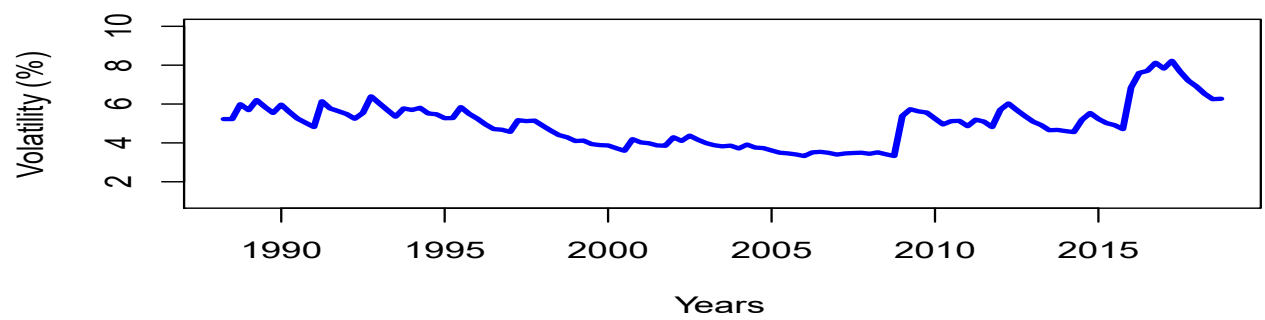



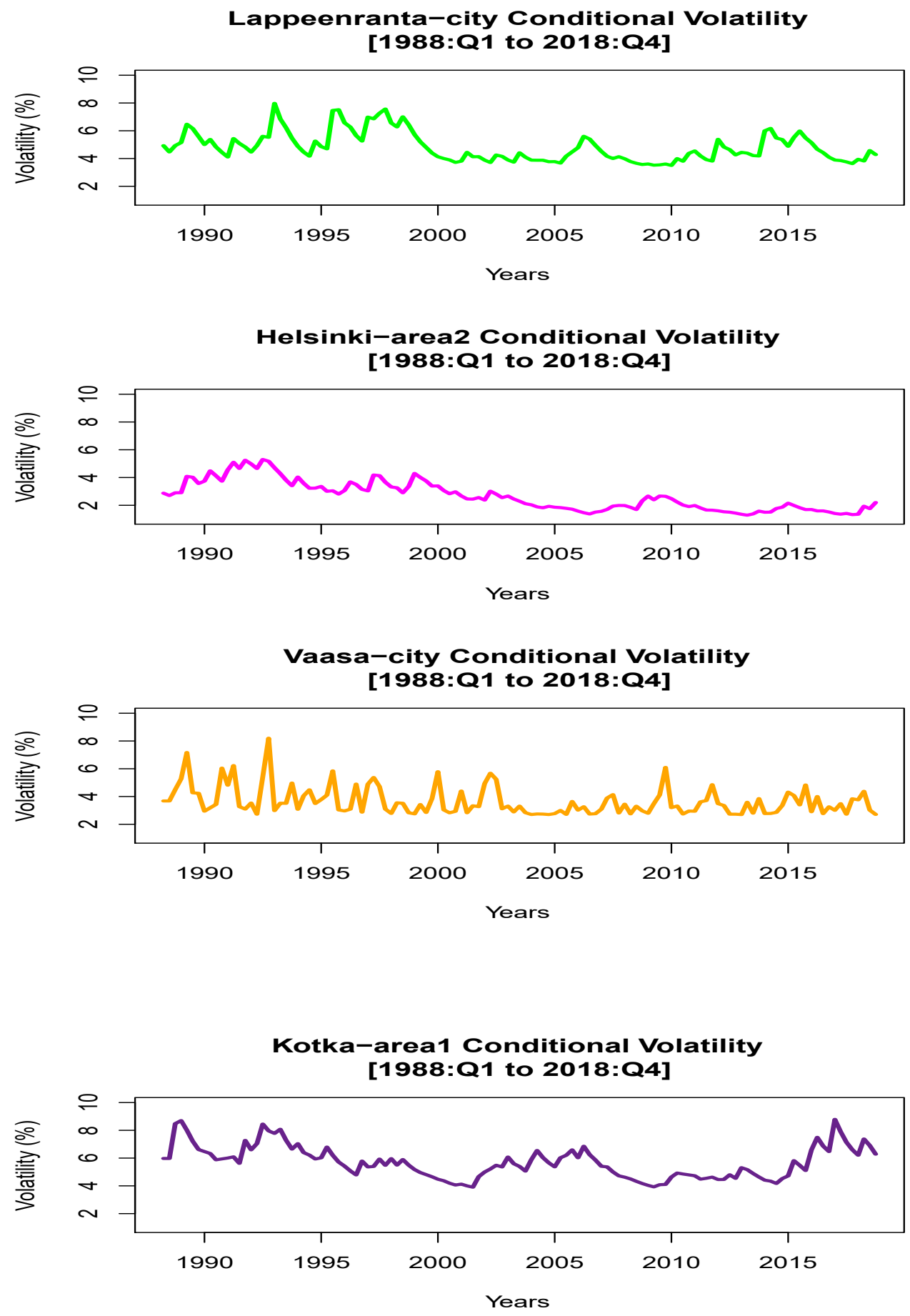

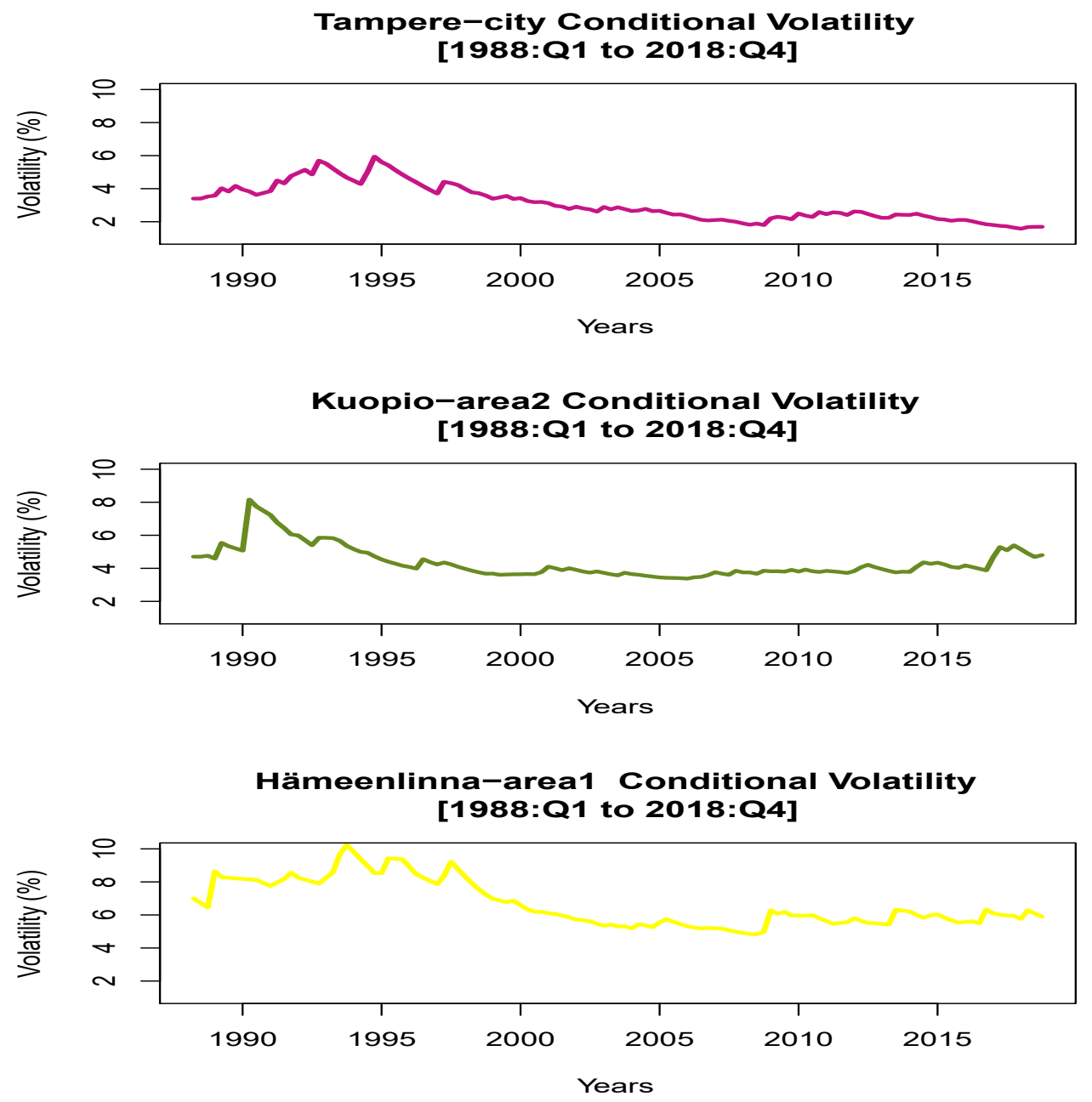

Figure 2: Conditional variance of housing volatility - Sample cities/sub-areas.

\section{Testing for GARCH-M effects}

Next, an analysis is conducted to examine the potential impact that the house price volatility may have on house price returns by estimating individual GARCH-M models for cities and sub-areas with significant ARCH effects.

Table 6 presents the $\lambda$ estimated coefficients with their standard errors (in parentheses). Mixed results on the sign of the significant risk-return impact are observed across cities and sub-areas in all three apartment types. Plus precisely, in the one-room flats category, out of twenty-eight cities/sub-areas exhibiting clustering effects, twenty-two have GARCH-M effects: twelve areas with a positive sign and ten with a negative sign. In the two-rooms flats category, out of twenty-seven cities/sub-areas with significant ARCH effects, nineteen have GARCH-M effects: fifteen areas with a positive sign and four areas with a negative sign. In the more than three rooms flats category, out of thirty-one cities/sub-areas exhibiting volatility clustering, twenty-five have GARCH-M effects: seventeen areas with 
a positive sign and eight areas with a negative sign. Note that no GARCH-M model could be fitted which yielded convergent estimates for Tutku-city in the two-rooms flats category.

As discussed earlier, a significant positive $\lambda$ implies that an increased risk leads to an increased mean return. Results confirm that there is evidence of a positive risk-return relationship in the regions of Oulu, Pori, Joensuu, Lappeenranta, and Kotka in the oneroom flats category. In the two-rooms flats category, the risk-return impact is positive in the regions of Lahti, Pori, Kuopio, Joensuu, Kovoula, and Lappeenranta. In the more than three rooms flats, the risk-return relationship is positive in the regions of Oulu, Jyväskylä, Seinäjoki, Lappeenranta, and Hämeenlinna. In all three apartment types, the risk-return impact is positive in Lahti and Lappeenranta cities. These results imply that these regions' investors are risk-averse and would require a higher return as a reward for the increased risk. For densely populated areas such as Helsinki, Tampere, and Turku, their housing citywide and sub-markets display mostly a negative risk-return effect; indicating that a higher conditional variance lowers returns in these regions. In other words, in these areas, periods with higher volatility may cause investors to believe that the future is riskier, which would give rise to higher savings and lower the risk premium.

These results are in line with the findings of Milles (2008), Milles (2011b), Morley and Thomas (2011), and Lin and Fuerst (2014), who documented mixed results on the sign of the risk-return relationship in the US, UK, and Canadian housing markets, respectively. Moreover, the results in most of the cities and sub-areas, especially in the two-rooms apartments type support Merton's (1973) hypothesis that investors (in this case Finnish housing investors) would demand a higher return to compensate the high risk. Furthermore, in some regions, especially in the one-room flats category, the results provide support to Glosten et al.'s (1993) argument that during volatile periods, investors may accept a lower return as the future would be more riskier. Lee (2017) did not find evidence to support the latter argument in the Australian housing market. The author argued that as the Australian housing market is dominated by home buyers and home owner-occupiers instead of housing investors (RBA, 2015); if the market is too volatile, investors may not accept a lower return. Instead, they may hold off their investment plans; the reason behind the strong positive relationship between risk and return in the whole Australian housing market.

However, this is not the case for the Finnish housing market, as discussed above. The plausible reason could be the fact that the Finnish housing market is dominated by investors; foreign as well as domestic. According to the Finnish Landlord Association's (2017) survey, Finnish residential property investments are no longer exclusively for professional investors. Ordinary people in Finland, especially younger residents, are increasingly buying flats as an investment rather than consumption (a place to live). Among the interviewed, 63 per cent own one or two apartments for rent; 33 per cent own three to ten apartments, and over three per cent own more than ten flats. Thus, when the housing market is highly volatile in one region, for instance, Kouvola area; the investor may accept a lower return as the future would be riskier, to invest in a positive risk-return market region such as Pori. Hence, the evidence of a negative risk-return relationship in some Finnish areas. Furthermore, these negative risk-return relationship results can also be supported by Hibbert et al.'s (2008) findings that in the stock market, the main explanation of the negative risk-return relation is the behaviour of traders (heterogeneous preferences).

In summary, the two-rooms apartments type have more cities/sub-areas with a positive housing risk-return relationship. Only four areas have a negative one; those are Helsinkiarea2, Helsinki-area3, Tampere-area1, and Jyväskylä-area1. This finding suggests that the two-rooms flats investors would require a higher return to compensate for the high risk. 
Moreover, there is no evidence of a geographical pattern with regards to the regions with a positive or a negative risk-return relationship; mixed results in the sign is observed across regions in all three apartments types. A finding which confirms, again as above, that a housing portfolio concentrated in one or several areas may be risky; however, diversifying a portfolio across Finland and by apartment type can lower risk.

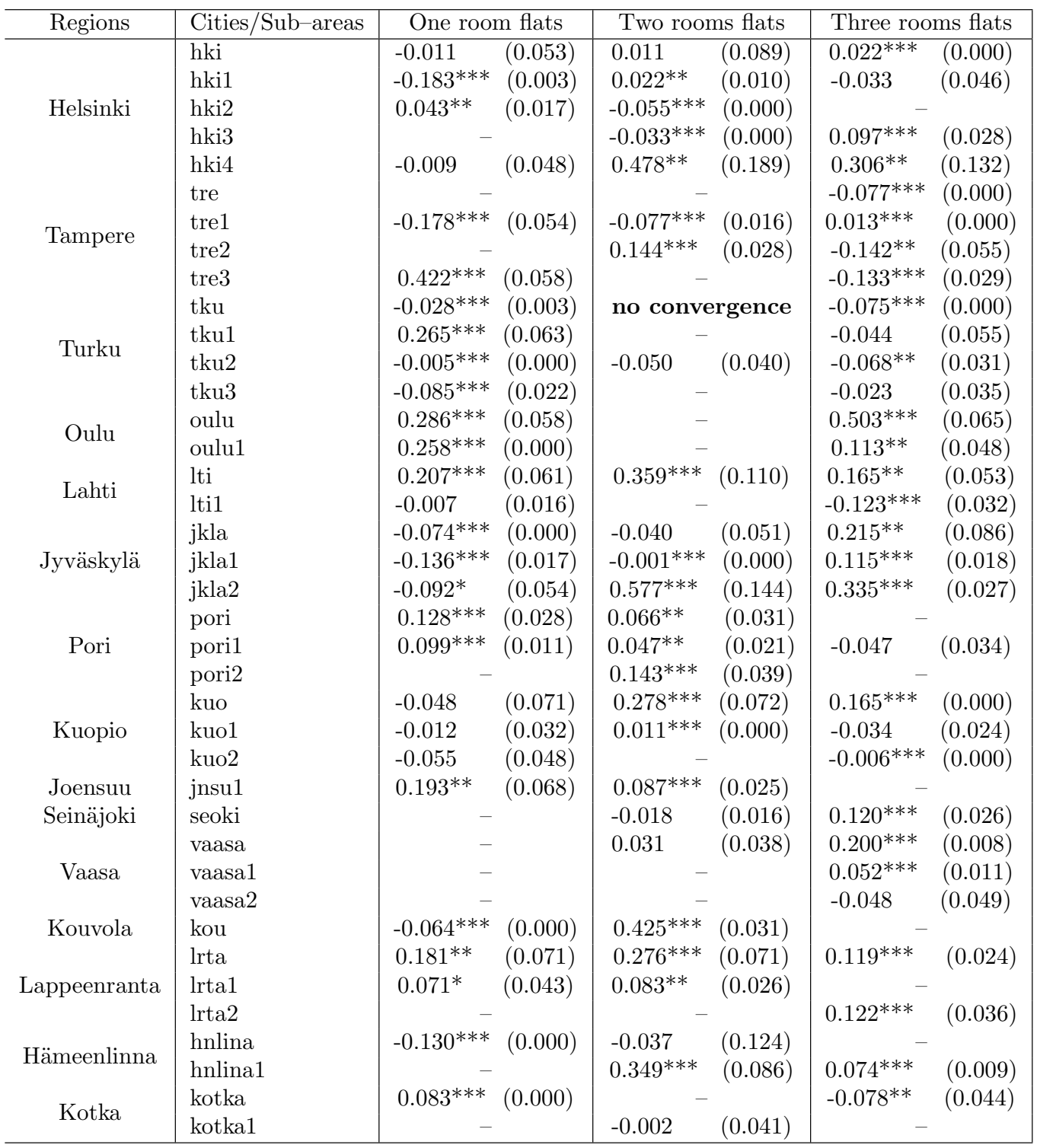

Notes: This table reports the estimates of the parameter $\lambda$ describing the nature of the relationship between house price return and volatility in individual GARCH-M model for each city and sub-area. The values in parentheses are the standard errors of the estimated parameters. ${ }^{*},{ }^{* *}$, and $* * *$ represent respectively $10 \%, 5 \%$, and $1 \%$ levels of significance.

Table 6: Risk-return estimated coefficients. 


\section{Testing for Asymmetric volatility}

Last, for cities and sub-areas exhibiting volatility clustering, the potentially asymmetric effects of shocks are investigated by estimating individual EGARCH models.

Table 7 displays the optimal specification of the EGARCH models, and their $\gamma$ estimated coefficients. The evidence of asymmetric impact of shocks on housing volatility is noted in all the cases; with significant threshold term in all three apartment types across all cities and sub-areas. The exception is Kuopio-area1 (highlighted) in the one-room flats category. Following Black's (1976) argument that negative shocks have more effect on the rise of the conditional volatility than positive innovations of equal magnitude; across all three apartment types, the leverage effects $(\gamma<0)$ exist in thirteen out of twenty-eight cities and sub-areas in the one-room flats category. In ten out of twenty-seven in the two-rooms flats category, and twelve out of thirty-one in the more than three rooms flats category. In these areas, leverage effects can be interpreted as follows: a drop in apartment type price will induce the rise of debt to housing equity, and thereby causes an increase in the house price volatility. Note again that no EGARCH model could be fitted which yielded convergent estimates for Tutku-city in the two-rooms flats category.

A striking geographical pattern is observed in the Helsinki region, where a significant positive sign of the asymmetric term is found in the whole region in both one-room and two-rooms apartments types, and in the part of the region (sub-market 3 and 4) in the more than three rooms apartments type. A result which is consistent with other studies on equity markets (Koutmos et al., 1993; Kassimatis, 2002; Apergis and Eleptherou, 2001). Although, this positive sign suggests that there is no leverage effect, however, it may reflect a speculative housing bubble as pointed out by Morley and Thomas (2011); which means that in a highly populated region such as Helsinki, high demand of these apartments types would lead to a dramatic rise in house prices, and hence, the housing bubble. Therefore, following Lin and Fuerst (2014) who found similar results in the populated Canadian provinces: Alberta, Quebec, and Saskatchewan; the same recommendation of designing local housing policies with the aim to counterbalance developing housing bubbles can be given to Finnish housing policymakers of the Helsinki region. A similar pattern in all three apartments types is also observed in Turku-area2 and Jyväskylä-area2. One key solution would be to implement a supply response to these types of apartments in these populated areas.

The above-discussed results are consistent with the findings of Milles (2008), Morley and Thomas (2011), Lee (2009), and Lin and Fuerst (2014) who documented asymmetric effects in the US, UK, Australian, and Canadian housing markets, respectively. The results also prove and confirm once more the effective performance of the EGARCH model in modelling asymmetric effects in the housing markets. 


\begin{tabular}{|c|c|c|c|c|c|c|c|}
\hline \multirow[b]{2}{*}{ Regions } & & \multicolumn{2}{|c|}{ One room flats } & \multicolumn{2}{|c|}{ Two rooms flats } & \multicolumn{2}{|c|}{ Three rooms flats } \\
\hline & Cities/sub-areas & Model & $\gamma$ & Model & $\gamma$ & Model & $\gamma$ \\
\hline \multirow{5}{*}{ Helsinki } & hki & $(1,3)$ & $0.762^{* * *}$ & $(2,3)$ & $1.062^{* * *}$ & $(2,2)$ & $-1.027^{* * *}$ \\
\hline & hki1 & $(2,2)$ & $0.502^{* * *}$ & $(2,3)$ & $1.695^{* * *}$ & $(3,1)$ & $-0.800 * * *$ \\
\hline & hki2 & $(1,1)$ & $0.100^{* * *}$ & $(2,3)$ & $1.257^{* * *}$ & - & - \\
\hline & hki3 & - & - & $(2,3)$ & $0.694^{* * *}$ & $(2,3)$ & $1.111^{* * *}$ \\
\hline & hki4 & $(2,3)$ & $0.324^{* * *}$ & $(1,3)$ & $1.255^{* * *}$ & $(2,2)$ & $0.372^{* * *}$ \\
\hline \multirow{4}{*}{ Tampere } & tre & - & - & - & - & $(2,3)$ & $0.432^{* * *}$ \\
\hline & tre1 & $(3,2)$ & $-0.342^{* * *}$ & $(1,3)$ & $-0.336^{* * *}$ & $(3,1)$ & $-0.339^{* * *}$ \\
\hline & tre2 & - & - & $(3,3)$ & $-0.298 * * *$ & $(3,1)$ & $1.566^{* * *}$ \\
\hline & tre3 & $(3,2)$ & $-0.218^{* * *}$ & - & - & $(2,2)$ & $0.747^{* * *}$ \\
\hline \multirow{4}{*}{ Turku } & tku & $(2,3)$ & $0.367^{* * *}$ & No convergence & - & $(3,2)$ & $-0.074^{* * *}$ \\
\hline & tku1 & $(3,2)$ & $-1.180^{* * *}$ & - & - & $(2,3)$ & $0.294^{* * *}$ \\
\hline & tku2 & $(2,3)$ & $0.896^{* * *}$ & $(2,3)$ & $0.532^{* * *}$ & $(1,3)$ & $0.366^{* *}$ \\
\hline & tku3 & $(3,3)$ & $0.001^{* * *}$ & - & - & $(2,3)$ & $1.035^{* * *}$ \\
\hline \multirow{2}{*}{ Oulu } & oulu & $(3,2)$ & $-0.335^{* * *}$ & - & - & $(1,3)$ & $0.797^{* * *}$ \\
\hline & oulu1 & $(2,3)$ & $-0.586^{* * *}$ & - & - & $(1,2)$ & $-0.324^{* * * *}$ \\
\hline \multirow{2}{*}{ Lahti } & lti & $(2,3)$ & $-0.221^{* * *}$ & $(2,2)$ & $-0.282^{* * *}$ & $(1,1)$ & $-0.377^{* * *}$ \\
\hline & lti1 & $(2,3)$ & $0.415^{* * *}$ & - & - & $(3,1)$ & $-0.829 * * *$ \\
\hline \multirow{3}{*}{ Jyväskylä } & jkla & $(3,2)$ & $0.722^{* * *}$ & $(3,1)$ & $-0.068 * * *$ & $(3,3)$ & $-0.402^{* * *}$ \\
\hline & jkla1 & $(3,1)$ & $-0.626 * * *$ & $(2,2)$ & $0.489^{* * *}$ & $(1,2)$ & $0.384^{* * *}$ \\
\hline & jkla2 & $(3,3)$ & $0.151^{* * *}$ & $(2,1)$ & $0.557^{* * *}$ & $(2,3)$ & $0.062^{* * *}$ \\
\hline \multirow{3}{*}{ Pori } & pori & $(2,3)$ & $0.544^{* * *}$ & $(2,3)$ & $1.275^{* * *}$ & - & - \\
\hline & pori1 & $(1,2)$ & $-0.883^{* * *}$ & $(3,3)$ & $-1.480^{* * *}$ & $(3,1)$ & $0.686^{* * *}$ \\
\hline & pori2 & - & - & $(1,1)$ & $0.972^{* * *}$ & - & - \\
\hline \multirow{3}{*}{ Kuopio } & kuo & $(3,1)$ & $-1.432^{* * *}$ & $(3,2)$ & $-0.985 * * *$ & $(3,3)$ & $-0.952^{* * *}$ \\
\hline & kuo1 & $(2,1)$ & 0.188 & $(3,1)$ & $-0.968^{* * *}$ & $(1,1)$ & $0.183^{* * *}$ \\
\hline & kuo2 & $(3,3)$ & $1.638^{* * *} *$ & - & - & $(2,2)$ & $-0.454^{* * *}$ \\
\hline Joensuu & jnsu1 & $(2,2)$ & $-0.454^{* * *}$ & $(1,3)$ & $-0.552^{* * *}$ & - & - \\
\hline \multirow[t]{2}{*}{ Seinäjoki } & seoki & - & - & $(1,1)$ & $0.557^{* *}$ & $(2,3)$ & $0.701^{* * *}$ \\
\hline & vaasa & - & - & $(3,1)$ & $0.926^{* * *}$ & $(2,1)$ & $-0.738^{* * *}$ \\
\hline \multirow[t]{2}{*}{ Vaasa } & vaasa1 & - & - & - & - & $(2,2)$ & $-0.344^{* * *}$ \\
\hline & vaasa 2 & - & - & - & - & $(3,3)$ & $0.039^{* * *}$ \\
\hline \multirow[t]{2}{*}{ Kouvola } & kou & $(1,3)$ & $0.170^{* * *}$ & $(2,1)$ & $0.861^{* * *}$ & - & - \\
\hline & lrta & $(2,2)$ & $-0.254^{* * *}$ & $(3,2)$ & $-0.202^{* * *}$ & $(2,2)$ & $0.330^{* * *}$ \\
\hline \multirow[t]{2}{*}{ Lappeenranta } & lrta1 & $(3,3)$ & $0.486^{* * *}$ & $(3,2)$ & $0.763^{* * *}$ & - & - \\
\hline & $\operatorname{lrta} 2$ & - & - & - & - & $(3,1)$ & $0.312^{* * *}$ \\
\hline \multirow{2}{*}{ Hämeenlinna } & hnlina & $(3,2)$ & $-0.866^{* * *}$ & $(2,3)$ & $0.887^{* * *}$ & - & - \\
\hline & hnlina1 & - & - & $(2,3)$ & $0.085^{* * *}$ & $(3,3)$ & $0.979 * * *$ \\
\hline \multirow{2}{*}{ Kotka } & kotka & $(2,1)$ & $-0.648^{* * *}$ & - & - & $(1,2)$ & $0.568^{* * *}$ \\
\hline & kotka1 & - & - & $(2,3)$ & $-0.002^{* * *}$ & - & - \\
\hline
\end{tabular}

Note: This table reports the optimal specification of the EGARCH model for each city and sub-area and their $\gamma$ estimated coefficients. A significant $\gamma$ implies asymmetry, and leverage effects exist if $\gamma<0 . *, * *$, and $* * *$ represent respectively $10 \%, 5 \%$, and $1 \%$ levels of significance.

Table 7: Asymmetric estimated coefficients.

\section{Conclusion and implications}

The literature on the assessment of volatility clustering, risk-return relationship, and asymmetric effects of the house prices is quite limited; compared to other assets such as stocks, despite housing having a dual role of investment and consumption. This article examines whether these financial properties are valid in the Finnish housing market, using quarterly house price indices from 1988:Q1 to 2018:Q4, for fifteen main regions in Finland.

The study has various major findings. First, strong evidence of volatility clustering (ARCH) effects is evident in over half of the cities and sub-areas in all three apartments types; indicating that apartments types prices in Finland are time-varying and clustered over time. Second, mixed results on the sign of the significant risk-return impact are observed across cities and sub-areas in all three apartments types; indicating that, in 
some regions, the Finnish housing investors are risk-reverse and would require a higher return to compensate the high risk. In other regions, during volatile periods, investors may accept a lower return as they think that the future would be riskier. Last, the evidence of the asymmetric impact of shocks on housing volatility is noted in almost all the cities and sub-areas housing markets. However, across all three apartments types, the leverage effects exist in few regions; indicating that a drop in apartment price will raise uncertainty, and hence house price volatility. Moreover, a geographical pattern is noticeable in the whole Helsinki region in both one-room and two-rooms flats categories, and in the part of the area in the more than three rooms flats category. These results in the Helsinki region serve as an "early warning" of a housing bubble.

The findings have some housing investment and policymakers implications. First, the strong evidence of ARCH effects suggests that housing investors, policymakers, and consumers should be aware of higher risks of substantial losses in house price returns during volatile periods. Moreover, they should monitor the asset volatility as it holds essential information. Second, mixed results in the sign of the risk-return relation observed across regions in all three apartments types recommend diversification of a housing portfolio across Finland and by apartment type; as the one concentrated in one or several areas may be risky. Last, the evidence of the asymmetric adjustment to shocks suggests that the Finnish housing market is more sensitive to bad news than good news. The Helsinki region' results indicate a speculative housing bubble, and it is recommended to the housing policymakers of these regions to address this issue in their housing policy designs.

In the standpoint of developing appropriate time series volatility forecasting models of this housing market; the study outcomes will be used in a forecasting procedure of the volatility dynamics of the studied types of dwellings. That is, as the model which fits better does not necessarily mean it will forecast well, an in-sample and out-of-sample forecasting performance of these short memory GARCH-types model will be compared and assessed to the long memory GARCH models such as the Fractionally Integrated GARCH (FIGARCH) model and the Component GARCH (CGARCH) model; to provide information regarding which forecasting methods deliver superior volatility forecasts of the studied types of apartments. 


\section{Appendices}

\begin{tabular}{|c|c|c|}
\hline Cities/Sub-areas & $\begin{array}{l}\text { Abbreviations for cities and sub- } \\
\text { areas }\end{array}$ & Postcode numbers \\
\hline Helsinki & hki & City area \\
\hline Helsinki-area1 & hki1 & $\begin{array}{l}100,120,130,140,150,160,170 \\
180,220,260\end{array}$ \\
\hline Helsinki-area2 & hki2 & $\begin{array}{l}200,210,250,270,280,290,300, \\
310,320,330,340,500,510,520, \\
530,540,550,560,570,580,590, \\
610,810,850,990\end{array}$ \\
\hline Helsinki-area2 & hki3 & $\begin{array}{l}240,350,360,370,400,430,440, \\
440,620,650,660,670,680,690, \\
730,780,790,800,830,840,950\end{array}$ \\
\hline Helsinki-area4 & hki4 & Other postcodes \\
\hline Tampere & tre & City area \\
\hline Tampere-area1 & tre1 & $\begin{array}{llll}33100, & 33180, & 33200, & 33210, \\
33230, & 33240, & 33250, & 33500, \\
33540 & & & \end{array}$ \\
\hline Tampere-area 2 & tre2 & $\begin{array}{llll}33270, & 33400, & 33530, & 33560, \\
33610, & 33700, & 33730, & 33820, \\
33900, & 34240 & & \end{array}$ \\
\hline Tampere-area3 & tre3 & Other postcodes \\
\hline Turku & tku & City area \\
\hline Turku-area1 & tku1 & $\begin{array}{l}20100, \quad 20500, \quad 20700, \quad 20810, \\
20900\end{array}$ \\
\hline Turku-area2 & tku2 & $\begin{array}{llll}20200, & 20250, & 20300, & 20380, \\
20400, & 20520, & 20720, & 20880, \\
20960 & & & \end{array}$ \\
\hline Turku-area3 & tku3 & Other postcodes \\
\hline Oulu & oulu & City area \\
\hline Oulu-area1 & oulu1 & $\begin{array}{lll}90100,90120, & 90130, & 90140, \\
90230,90400, & 90410, & 90420, \\
90510 & & \end{array}$ \\
\hline Oulu-area2 & oulu2 & Other postcodes \\
\hline Lahti & lti & City area \\
\hline Lahti-area1 & lti1 & $\begin{array}{llll}15100, & 15110, & 15140, & 15160, \\
15320, & 15340, & 15610, & 15850, \\
15900 & & & \end{array}$ \\
\hline Lahti-area2 & lti2 & Other postcodes \\
\hline Jyväskylä & jkla & City area \\
\hline Jyväskylä-area1 & jkla1 & $\begin{array}{l}40100, \quad 40200, \quad 40500, \quad 40520 \\
40530,40600,40700,40720\end{array}$ \\
\hline Jyväskylä-area2 & jkla2 & Other postcodes \\
\hline Pori & pori & City area \\
\hline
\end{tabular}




\begin{tabular}{|c|c|c|}
\hline Cities/Sub-areas & $\begin{array}{l}\text { Abbreviations for cities and sub- } \\
\text { areas }\end{array}$ & Postcode numbers \\
\hline Pori-area1 & pori1 & $\begin{array}{l}28100, \quad 28130, \quad 28300, \\
28540,28660,28900\end{array}$ \\
\hline Pori-area2 & pori2 & Other postcodes \\
\hline Kuopio & kuo & City area \\
\hline Kuopio-area1 & kuo1 & $\begin{array}{l}70100, \quad 70110, \\
70800,70840\end{array}$ \\
\hline Kuopio-area2 & kuo2 & Other postcodes \\
\hline Joensuu & jnsu & City area \\
\hline Joensuu-area1 & jnsu1 & $80100,80110,80200,80220$ \\
\hline Joensuu-area2 & jnsu2 & Other postcodes \\
\hline Seinajöki & seoki & City area \\
\hline Vaasa & vaasa & City area \\
\hline Vaasa-area1 & vaasa1 & $65100,65170,65200,65410$ \\
\hline Vaasa-area2 & vaasa 2 & Other postcodes \\
\hline Kouvola & kou & City area \\
\hline Lappeenranta & lrta & City area \\
\hline Lappeenranta-area1 & lrta1 & $\begin{array}{l}53100, \quad 53130, \quad 53500, \quad 53600, \\
53900,55330\end{array}$ \\
\hline Lappeenranta-area2 & $\operatorname{lrta} 2$ & Other postcodes \\
\hline Hämeenlinna & hnlina & City area \\
\hline Hämeenlinna-area1 & hnlina1 & $\begin{array}{l}13100, \quad 13130, \quad 13200, \\
13270\end{array}$ \\
\hline Hämeenlinna-area2 & hnlina2 & Other postcodes \\
\hline Kotka & kotka & City area \\
\hline Kotka-area1 & kotka1 & $48100,48210,48310,48710$ \\
\hline Kotka-area2 & kotka2 & Other postcodes \\
\hline
\end{tabular}

Source: Statistics Finland

Table 8: Regional division by postcode numbers.

\section{References}

André, C. and García, C. (2012). Housing Price and Investment Dynamics in Finland, Technical report, OECD Economics Department Working Papers, No.962, OECD Publishing.

URL: http://dx.doi.org/10.1787/5k98rwldjr44-en

Apergis, N. and Eleptherou, S. (2001). Stock Returns and Volatility Evidence from the Athens Stock Market Index, Journal of Economics and Finance 25: 50-61.

Bank of Finland (2018). Helibor and Euribor rates.

URL: https://www.suomenpankki.fi/en/Statistics/interest-rates/tables/

Bekaert, G. and Wu, G. (2000). Asymmetric volatility and risk in equity markets, Review of Financial Studies 13: 1-42.

Black, F. (1976). Studies of Stock Market Volatility Changes, Proceedings of the 1976 Meetings of the American Statistical Association, Business and Economics Statistics Section, pp. 177-181.

Bollerslev, T. (1986). Generalized autoregressive conditional heteroscedasticity, Journal of Econometrics 31(3): 307-327. 
Bollerslev, T., Chou, R. Y. and Kroner, K. F. (1992). ARCH modeling in Finance: A Review of the Theory and Empirical Evidence, Journal of Econometrics 52: 1-2, $5-59$.

Campbell, J. Y. and Hentschell, L. (1992). No News is Good News: An asymmetric model of changing volatility is stock returns, Journal of Financial Economics 31: 281-318.

Cannor, S., Miller, N. and Pandher, G. S. (2006). Risk and return in US housing market: a cross-sectional asset-pricing approach, Real State Economics 34(4): 519-552.

Christie, A. A. (1982). The Stochastic Behavior of Common Stock Variances-Value, Leverage and Interest Rate Effects, Journal of Financial Economics 10: 407-432.

Coskun, Y. and Ertugrul, H. M. (2016). House price return volatility patterns in Turkey, Istanbul, Ankara and Izmir, Journal of European Real Estate Research 8(1): 26-51.

Dolde, W. and Tirtiroglu, D. (1997). Temporal and spatial information diffusion in real estate price changes and variances, Real Estate Economics 25(4): 539-565.

Dolde, W. and Tirtiroglu, D. (2002). Housing price volatility changes and their effects, Real Estate Economics 30: 41-66.

Engle, R. F. (1982). Autoregressive conditional heteroscedasticity with estimates of variance of United Kingdom inflation, Econometrica 50(4): 987-1007.

Engle, R. F., Lilien, D. M. and Robins, R. P. (1987). Estimating Time Varying Risk Premia in the Term Structure: The ARCH-M Model, Econometrica 55(2): 391-407.

Engle, R. F. and Ng, V. K. (1993). Measuring and testing the impact of news on volatility, Journal of Finance 48(5): 1749-1778.

Finnish Landlord Association (2017). A survey among Finnish private landlords.

URL: https://vuokranantajat.fi/asunntosijoittaminen/tutkimusket/vuokranantaja2017/

French, K. R., Schwert, G. W. and Stambaugh, R. (1987). Expected stock returns and volatility, Journal of Financial Economics 19: 3-29.

Ghalanos, A. (2019). rugarch: Univariate GARCH models. R package version 1.4-1.

Glosten, L., Jagannathan, R. and Runkle, D. (1993). On the Relation between the Expected Value and the Volatility of the Norminal Excess Return on Stocks, Journal of Finance 68: 1179-1801.

Graves, S. (2019). Companion to Tsay (2005) Analysis of Financial Time Series. R package version 0.4-6.

Guo, H. and Nelly, C. J. (2008). Investigating the intertemporal risk-return relation in international stock markets with the component GARCH model, Economics Letters 99: $371-374$.

Hibbert, A. M., Daigler, R. T. and Dupoyet, B. (2008). A behaviour explanation for the negative asymmetric return-volatility relation, Journal of Banking $\mathcal{E}$ Finance pp. 322254-322266. 
Hossain, B. and Latif, E. (2009). Determinants of housing price volatility in Canada: a dynamic analysis, Applied Economics 41(27): 3521-3531.

Kaleva, H. (2019). The Finnish Property Market Report, Technical report, KTI Property Information Ltd.

Kassimatis, K. (2002). Financial Liberalisation and Stock Market Volume in Selected Developing Markets, Applied Financial Economics 12: 389-394.

Katsiampa, P. and Begiazi, K. (2019). An empirical analysis of the Scottish housing market by property type, Scottish Journal of Political Economy .

URL: DOI: 10.1111/sjpe.12210

Kivistö, J. (2012). An assessment of housing price developments against various measures, Technical report, Bank of Finland Bulletin.

Koutmos, G., Negakis, C. and Theodossiou, P. (1993). Stochastic Behaviour of the Athens Stock Exchange, Applied Financial Economics 3: 119-126.

KTI (Autumn, 2019). KTI Market Review, Technical report, KTI Property Information Ltd.

Lee, C. L. (2009). Housing price volatility and its determinants, International Journal of Housing Markets and Analysis 2(3): 293-308.

Lee, C. L. (2017). An examination of the risk-return relation in the Australian housing market, International Journal of Housing Markets and Analysis 10(3): 431-449.

Lee, C. L. and Reed, R. (2014a). The relationship between housing market intervention for the first-time buyers and house price volatility, Housing Studies 29(8): 1073-1095.

URL: doi: 10.1080/02673037.2014.927420

Lee, C. L. and Reed, R. (2014b). Volatility decomposition of Australian housing prices, Journal of Housing Research 23(1): 21-43.

Lin, P.-T. and Fuerst, F. (2014). Volatility clustering, risk-return relationship, and asymmertic adjustment in the Canadian housing market, Journal of Real Estate Portifolio Management 20(1): 37-46.

Mcleod, A. I. and Li, W. K. (1983). Diagnostic checking ARMA time series models using squared - residual autocorrelations, Journal of Time Series Analysis 4(4): 269-273.

Merton, R. C. (1973). An intertemporal capital asset pricing models, Econometrica pp. $41867-41887$.

Miller, N. and Peng, L. (2006). Exploring metropolitan housing price volatility, The Jouarnal of Real Estate Finance and Economics 33(1): 5-18.

Milles, W. (2008). Volatility clustering in US home prices, Journal of Real Estate Research 30(1): 73-90.

Milles, W. (2011). Long-Range Dependence in U.S Home Price Volatility, Journal of Real Estate Finance and Economics 42: 329-347.

Milles, W. (2011b). Clustering in UK home prices volatility, Journal of Housing Research 20(1): $87-101$. 
Morley, B. and Thomas, D. (2011). Risk-return relationships ans asymmetric adjustment in the UK housing market, Applied Financial Economics 21(10): 735-742.

Nelson, D. B. (1991). Conditional Heteroskedasticity in Asset Returns: A New Approach, Econometrica 55: 703-708.

Oikarinen, E. (2009a). Household borrowing and metropolitan house price dynamics Empirical evidence from Helsinki, Journal of Housing Economics 18(2): 126-139.

Oikarinen, E. (2009b). Interaction between housing prices and household borrowing: The Finnish case, Journal of Banking \& Finance 33(4): 747-756.

R Core Team (2019). R: A Language and Environment for Statistical Computing, $\mathrm{R}$ Foundation for Statistical Computing, Vienna, Austria.

URL: https://www.R-project.org/

RBA (2015). Submission to the Inquiry into Home Ownership, Technical report, Reserve Bank of Australia, Sydney.

URL: $\quad$ www.rba.gov.au/publications/submissions/housing-and-housingfinance/inquiry-into-home-ownership/pdf/inquiry-into-home-ownership.pdf

Statistics Finland (2016). Households' assets, Technical report. Last checked: 10/09/2019.

URL: http://www.stat.fi/til/vtutk/2016/vtutk-2016-2018-06-05-tie-001-en.html

Statistics Finland (2019). Building and dwelling production, Technical report. Last checked: 10/09/2019.

URL: $h t t p: / / w w w . s t a t . f i / t i l / r a s / i n d e x-e n . h t m l$

Statistics Finland Overview (2018). 2018 overview, household-dwelling units and housing conditions, Technical report. Last checked: 28/01/2020.

URL: $\quad$ http://www.stat.fi/til/asas/2018/011/asas-2018-01-2019-10-10-kat-002en.html

Stevenson, S. (2002). An examination of volatility spillovers in REIT returns, Journal of Real Estate Portfolio Management 8(3): 229-238.

Tsai, I.-C. and Chen, M.-C. (2009). The asymmetric volatility of house prices in the UK, Property Management 27(2): 80-90.

Tsai, I.-C., Chen, M.-C. and Ma, T. (2010). Modelling house price volatility states in the UK by switching ARCH models, Applied Economics 42(9): 1145-1153.

Tsay, R. S. (2013). An introduction to analysis of financial data with $R$, John Wiley \& Sons, Inc., Hoboken, New Jersey.

Willcocks, G. (2010). Conditional variances in UK regional house prices, Spatial Economic Analysis 5(3): 339-354. 